\title{
¿Independencia Judicial según los Jueces Constitucionales? un Análisis Conceptual a partir de las Decisiones del Supremo Tribunal Federal de Brasil y de la Corte Constitucional de Colombia
}

\author{
A Independência Judicial segundo os Juízes Constitucionais? uma Análise \\ Conceitual baseada nas Decisões do Supremo Tribunal Federal do \\ Brasil e da Corte Constitucional da Colômbia
}

\section{Independence of the Judiciary according to the Constitutional Judges? a Conceptual Analysis based on Brazilian Supreme Federal Court and Colombian Constitutional Court}

\author{
William Iván Gallo Aponte \\ Daniel Castanha de Freitas ** \\ Vivian Cristina Lima López Valle*
}

* Doctorando y Maestro en Derecho Económico y Desarrollo por la Pontifícia Universidade Católica do Paraná - PUCPR (Curitiba, Brasil). Abogado por la Universidad Externado de Colombia (Bogotá D.C, Colombia). Se desempeñó como profesor investigador-becario de la Universidad Externado de Colombia. Actualmente es investigador de la Universidad Externado de Colombia y del Núcleo de Pesquisas em Politicas Públicas e Desenvolvimento Humano - NUPED de la PUCPR. Coordinador Adjunto de la Especialización en Licitaciones y Contratos Administrativos de la PUCPR. Investigador auxiliar en el proyecto ICCAL-Derecho Administrativo del Max Planck Institute for Comparative Law and International Law. Universidad Externado de Colombia, Colômbia. E-mail: <williamg.aponte@gmail.com>. https://orcid.org/0000-0001-7157-6291.

* Doctorando y Maestro en Derecho Económico y Desarrollo por la Pontifícia Universidade Católica do Paraná - PUCPR (Curitiba, Brasil). Profesor de Derecho Administrativo de la FAE- Centro Universitário (Curitiba, Brasil). E-mail: <advcastanha@gmail.com>. https://orcid.org/0000-0003-2984-7099

*** Profesora Titular de Derecho Administrativo de la Pontifícia Universidade Católica do Paraná - PUCPR (Curitiba, Brasil). Adelanta estancia postdoctoral en la Universitat Rovira i Virgili en España. Doctora y Magister en Derecho del Estado por la Universidad Federal de Paraná - UFPR. Especialista en Contratación Pública por la Universidad de Coimbra en Portugal. Especialista en Derecho Administrativo por el Instituto Brasilero de Estudios Jurídicos- IBEJ. Coordinadora del Curso de Derecho de la Pontificia Universidad Católica de Paraná. Coordinadora del Curso de Especialización en Licitaciones y Contratos de la Pontificia Universidade Católica de Paraná - PUCPR. Miembro del Instituto Paranaense de Direito Administrativo y del Instituto de Direito Romeu Felipe Bacellar. Miembro de la Comisión de Gestión Pública de la Orden de Abogados de Brasil- Sección Paraná Abogada especializada en Derecho Público. E-mail: <vivian.lima@pucpr.br>. https://orcid.org/00000002-5793-2912 
1 Introducción. 2 La independencia judicial en el Estado Social de Derecho: consideraciones teóricas. 3 La independencia judicial según el Supremo Tribunal Federal de Brasil y la Corte Constitucional de Colombia. 3.1 Presupuestos, concepto y naturaleza jurídica. 3.2 Características, tipologías, sentidos y facetas de la independencia judicial. 4 iJueces independientes según quién? ¿cómo? ¿para quién? La independencia judicial y la actuación de los tribunales constitucionales en tiempos actuales. 5. Consideraciones finales. Referencias.

\section{RESUMEN}

Objetivo: El presente artículo tiene por objetivo analizar la manera y la forma como el Supremo Tribunal Federal de Brasil y la Corte Constitucional de Colombia definen, caracterizan o fundamentan la independencia judicial.

Metodología: Se utiliza una metodología deductiva, descriptiva y comparada, conjugada con una técnica de investigación empírica jurisprudencial y de documentación indirecta doctrinaria y normativa.

Resultados: Se concluye que: (1) Aunque existen elementos comunes, persiste una preocupación sobre la competencia atribuida por parte de los tribunales constitucionales en la definición y el entendimiento de la independencia judicial, siendo saludable que se someta su entendimiento a la Constitución y la ley, pues el juez en su condición humana es falible; (2) Más allá de entender la imparcialidad, la objetividad y de considerar la deliberación, la participación directa de los ciudadanos en el proceso de decisión, así como otros instrumentos, puede ser una idea sana y racional para mitigar el excesivo poder judicial; (3) El destinatario de la garantía de la independencia es la sociedad, pero no solo el que tiene acceso y conocimiento a la justicia, sino todos en condiciones de igualdad; (4) Superándose la posición de la supremacía del poder judicial, la teoría del principio negativo de Sieyès sobre le pouvoir constituant, brinda un análisis al fomento de un constitucionalismo que permite a las otras ramas electas del gobierno tomar y ejecutar sus propias decisiones.

Contribuciones: El artículo profundiza sobre la morfología de la independencia judicial. Si bien usualmente se identifica como un principio genérico, no por eso menos fundamental del Estado Social de Derecho, la investigación contribuye al sumergirse en la profundidad de su implicancia como principio, el sentido y las fuentes de su invocación genérica, sus presupuestos teóricos, sus perspectivas, la legitimidad de sus destinatarios y titulares. En general, sobre los límites, las formas y las estructuras, más aún cuando son los propios tribunales constitucionales quienes lo invocan, particularmente la Corte Constitucional de Colombia y el Supremo Tribunal Federal de Brasil.

Palabras clave: Independencia judicial. Autonomía de los jueces. Tibunales constitucionales. Derechos sociales. Poder judicial. 
¿Independencia judicial según los jueces constitucionales? un análisis conceptual a partir de las decisiones del Supremo Tribunal Federal de Brasil y de la Corte Constitucional de Colombia

\section{ABSTRACT}

Objective: The objective of this article is to analyze the manner and form in which the Brazilian Federal Supreme Court and the Colombian Constitutional Court define, characterize or support judicial independence.

Methodology: A deductive, descriptive and comparative methodology is used, combined with an empirical jurisprudential research technique and indirect doctrinal and normative documentation.

Results: This paper concluded that: (1) Although there are common elements, there persists a concern about the competence attributed by the constitutional courts in the definition and understanding of judicial independence, being healthy to submit their understanding to the Constitution and the law, since the judge in his human condition is fallible; (2) Beyond understanding impartiality, objectivity and considering deliberation, direct participation of citizens in the decision-making process, as well as other instruments, may be a healthy and rational idea to mitigate the excessive judicial power; (3) The addressee of the guarantee of independence is society, but not only the one who has access and knowledge to justice, but everyone on equal terms; (4) Overcoming the position of the supremacy of the judiciary, Sieyès' theory of the negative principle of le pouvoir constituant, provides an analysis to the promotion of a constitutionalism that allows the other elected branches of government to make and execute their own decisions.

Contributions: The article elaborates on the morphology of judicial independence. Although it is usually identified as a generic principle, not for that reason less fundamental of the Social State of Law, the research contributes by diving into the depth of its implication as a principle, the meaning and sources of its generic invocation, its theoretical assumptions, its perspectives, the legitimacy of its addressees and holders. In general, on the limits, forms and structures, even more so when it is the constitutional courts themselves who invoke it, particularly the Colombian Constitutional Court and Brazilian Federal Supreme Court.

Keywords: Independence of the judiciary. Judicial autonomy. Constitutional Courts. Social rights. Judicial Power.

\section{RESUMO}

Objetivo: $O$ presente artigo objetiva analisar a maneira e a forma como o Supremo Tribunal Federal do Brasil e a Corte Constitucional da Colômbia definem, caracterizam ou fundamentam a independência judicial.

Metodologia: Utiliza-se uma metodologia dedutiva, descritiva e comparativa, combinada com uma técnica de pesquisa jurisprudencial empírica e documentação doutrinária e 
normativa indireta.

Resultados: Conclui-se que: (1) Embora existam elementos comuns, persiste a preocupação com a competência atribuída pelos tribunais constitucionais na definição e entendimento da independência judicial, sendo saudável submeter seu entendimento à Constituição e à lei, pois o juiz em sua condição humana é falível; (2) Além de compreender a imparcialidade, objetividade e considerar a deliberação, a participação direta dos cidadãos no processo decisório, bem como outros instrumentos, pode ser uma ideia saudável e racional para mitigar o excessivo poder judicial; (3) $O$ destinatário da garantia de independência é a sociedade, o povo, mas não apenas aquele que tem acesso e conhecimento à justiça, mas todos em igualdade de condições; (4) Superando-se a posição de supremacia do judiciário, a teoria de Sieyès do princípio negativo de le pouvoir constituant, fornece uma análise para a promoção de um constitucionalismo que permita aos outros poderes eleitos tomar e executar suas próprias decisões.

Contribuições: $\mathrm{O}$ artigo desenvolve a morfologia da independência judicial. Embora seja geralmente identificada como um princípio genérico, não por isso menos fundamental do Estado Social de Direito, a pesquisa contribui mergulhando na profundidade de sua implicação como princípio, o significado e as fontes de sua invocação genérica, seus pressupostos teóricos, suas perspectivas, a legitimidade de seus destinatários e detentores. Em geral, sobre os limites, formas e estruturas, ainda mais quando são os próprios tribunais constitucionais que a invocam, particularmente a Corte Constitucional da Colômbia e o Supremo Tribunal Federal do Brasil.

Palavras-chave: Independência judicial. Autonomia dos juízes. Tribunais constitucionais. Direitos sociais. Judiciário.

\section{INTRODUCCIÓN}

¿Quién debe definir qué es la independencia judicial? ¿Cuáles son sus fundamentos? ¿Cómo se puede garantizar? ¿Cuáles son las características que la identifican? ¿Existe un consenso alrededor de su entendimiento? Estas y otras provocaciones retóricas parecen tener a simple vista una respuesta unívoca. No obstante, un real entendimiento de la independencia judicial y de todos los elementos que de ella se desprenden necesitan adecuarse a un análisis de metodología y actualidad.

La consolidación del Estado de Derecho, y a partir de ahí, el reconocimiento de que es necesario dividir y distribuir el poder so pena de recaer en manos de una autoridad tirana, son algunas de las bases sobre las cuales se sustenta el principio de la independencia judicial. Su importancia ha sido tal, que teóricos y académicos resaltan su relevancia al 
¿Independencia judicial según los jueces constitucionales? un análisis conceptual a partir de las decisiones del Supremo Tribunal Federal de Brasil y de la Corte Constitucional de Colombia

plantear argumentos e ideas para el diseño y la arquitectura de las instituciones políticas y jurídicas.

No obstante, la invariabilidad de posiciones que surge alrededor de su entendimiento, no por esto, que impida la identificación de elementos comunes, han alentado a que jueces y tribunales en su función de "guardianes de la Constitución" desplieguen todo un bagaje argumentativo alrededor de la independencia judicial. En últimas, según su juicio preliminar, es sobre ellos que recae la ejecución y materialización del principio. La realidad es divergente, los tiempos en los que el constitucionalismo y el neoconstitucionalismo han tomado protagonismo, han cedido importantes facultades en manos de los jueces, las cuáles, como se verá en este escrito, desbordan lo que originariamente se les ha conferido.

Por esa razón, el presente trabajo pretende hacer un análisis sobre la manera y la forma en que los tribunales constitucionales, de manera concreta, el Supremo Tribunal Federal de Brasil y la Corte Constitucional de Colombia, definen, caracterizan o fundamentan la independencia del juez. Ese análisis responde y dialoga no sólo con algunos de los teóricos clásicos que inspiraron las constitucionales modernas, sino también, con los problemas y los riesgos presentes dentro y alrededor del ejercicio de la función hermenéutica en la administración de justicia.

A partir de una metodología deductiva, descriptiva y comparada: Brasil-Colombia, conjugada con una técnica de investigación empírica y de documentación indirecta, esto es, a partir de decisiones del Supremo Tribunal Federal y la Corte Constitucional, así como de referencias bibliográficas y normativas. El presente trabajo, en primer lugar, propone y expone determinadas consideraciones teóricas acerca de la independencia judicial y su papel en el Estado Social de Derecho.

En segundo lugar, centrándose el objeto de este escrito, expone y unifica el desarrollo teórico elaborado por la jurisprudencia del Supremo Tribunal Federal y la Corte Constitucional sobre la independencia judicial. Los fundamentos, definición, naturaleza jurídica, las características, tipologías, sentidos y facetas.

Finalmente, previo a las consideraciones finales, se permite dar una aproximación orientadora a las preguntas ijueces independientes según quién? ¿cómo? ¿para quién? Explorando casos recientes de la jurisprudencia del Supremo Tribunal Federal y la Corte Constitucional que ponen en evidencia la necesidad de hacer esos cuestionamientos, así como posturas teóricas que pretenden dar sentido y norte a estas preguntas. 


\section{LA INDEPENDENCIA JUDICIAL EN EL ESTADO SOCIAL DE DERECHO: CONSIDERACIONES TEÓRICAS}

Entre 1787 y 1788, Alexander Hamilton, James Madison y John Jay escribieron bajo el anonimato El federalista o The Federalist Papers, una serie de ochenta y cinco artículos publicados en varios periódicos de manera simultánea, para incitar a los ciudadanos de Nueva York a ratificar la Constitución de Filadelfia de 1787. De igual modo, más allá de su propósito instrumental como un tratado sobre teoría política en torno a la elaboración de la Constitución estadounidense, El Federalista representó una contribución a la propaganda de partidarios y opositores del nuevo esquema constitucional, orientada a atender ciertas preocupaciones, entre otras: la protección de la libertad individual frente a la interferencia del poder y sus límites frente a quienes lo detentan (Cfr. COOK; DIETZE, 1961, p. 420422; GARCÍA, 2007, p. 33-59).

Dentro de ese compendio de comentarios e interpretaciones sobre el texto constitucional, la organización del poder judicial, su administración, responsabilidad, la distribución de su autoridad y la extensión de sus poderes tomó relevancia (HAMILTON; MADISON; JAY, 2018, p. 47-48). En primer lugar, analizaron las objeciones de los adversarios de la Constitución de Filadelfia en cuanto a la violación de la independencia del ejecutivo, el legislativo y el judicial. Dichos adversarios argumentaban que la distribución de los poderes era tal, que se destruía la simetría del poder en favor de la tiranía y en perjuicio de la libertad.

Lo cierto para los autores, siguiendo a Montesquieu y su análisis sobre la Constitución británica, era que esa objeción era infundada de acuerdo con los fundamentos de la libertad. Para Montesquieu, los poderes ejecutivo, legislativo y judicial, no se encuentran totalmente separados y diferenciados entre ellos. Por ejemplo, era notorio como el titular del ejecutivo formaba parte de la autoridad legislativa en términos de prerrogativas para la conclusión de los tratados, y como los miembros del poder judicial eran nombrados y destituidos por el ejecutivo con la aprobación de las cámaras en el legislativo.

Esta relación intrínseca entre los departamentos o poderes llevó a Madison a interpretar la visión de Montesquieu, quién argüía que, si los poderes legislativo y judicial se identificaban en una misma persona o en el mismo cuerpo colegiado no puede haber libertad, por cuanto pueden surgir temores de que el monarca o el parlamento decreten leyes tiránicas con el objetivo de ejecutarlas de modo tiránico. 
¿Independencia judicial según los jueces constitucionales? un análisis conceptual a partir de las decisiones del Supremo Tribunal Federal de Brasil y de la Corte Constitucional de Colombia

Bajo el sentir de Madison, tal argumento no quiere decir que el ejecutivo, el legislativo y el judicial no deban tener una intervención parcial o cierto dominio en los actos del uno o del otro. Por el contrario, la visión de Montesquieu se fundaba sobre la base de que si el rey, titular del ejecutivo hubiera poseído al mismo tiempo todo el poder legislativo o la administración superior de la justicia, los principios fundamentales de una Constitución libre se hallarían subvertidos.

Dicho de otro modo, si el poder de juzgar estuviese unido al poder de legislar, la vida y la libertad del súbdito se verían expuestas a un mandato arbitrario, pues el juez sería el legislador. De igual modo, si estuviese unido al ejecutivo, el actuar del juez sería conducido como la violencia de un opresor. Así, Madison en su interpretación deduce que es imposible pensar las constituciones de los Estados sin que los departamentos del poder se encuentren aislados y distintos en su totalidad. No obstante, en términos de garantizar la libertad de los ciudadanos de un gobierno tiránico y concentrado, es importante concordar en que los poderes propios del legislativo, el ejecutivo y el judicial no deben ser administrados ni directa ni completamente por cualquiera de los otros.

Asimismo, que la influencia permitida no puede ser preponderante en lo que se refiere a la administración de cada uno de los poderes. Si el poder tiende a extenderse con la finalidad de tomar protagonismo sobre otro, se le debe refrenar de manera eficaz atendiendo a los limites asignados. De acuerdo con Madison, el análisis sobre la defensa contra las extralimitaciones de los poderes constituye un problema.

Madison se preguntaba si era suficiente señalar en la Constitución los límites de los poderes, tal como lo hicieron la mayoría de las constituciones americanas, o, por el contrario, ¿se requiere de una defensa más adecuada en favor de los más débiles y en contra de los más poderosos? A su juicio, la experiencia demuestra que la sola determinación en el papel constitucional de los límites de los poderes no es suficiente para la salvaguarda contra las usurpaciones de la concentración tiránica y singularizada de los poderes.

Por el contrario, tal como lo deja de presente en El Federalista 49, si el pueblo constituye la única fuente legítima del poder y de él emanan los fundamentos constitucionales sobre las facultades de los distintos poderes, se debe volver a la autoridad originaria: el pueblo, cada vez que se quiera ampliar, disminuir o reformar los poderes. Asimismo, cuando cualquiera de los poderes invada los derechos constitucionales de los otros. En otras palabras, una propuesta frente a la forma de evitar las usurpaciones tiránicas de los más fuertes es acudiendo al pueblo. ${ }^{1}$

\footnotetext{
${ }^{1}$ Madison justifica su propuesta del poder originario, atendiendo a las notas interpretativas de Jefferson sobre la Constitución del Estado de Virgina. En su análisis, si bien la Constitución declaró que los tres
} 
Sin embargo, tal como lo resalta Madison, la idea de que sea el pueblo el medio ordinario para mantener los límites constitucionales de los poderes, no presenta una solución que genere plena conformidad y aceptación. Por un lado, porque es necesario hacer un análisis previo sobre la forma en que se han abierto los caminos para que la decisión del pueblo se manifieste en ocasiones ordinarias y extraordinarias. Por otro, más sustancial, sentado sobre el fundamento de la pasión pública, consiste en que, si se somete de manera frecuente las cuestiones constitucionales a la decisión de toda la sociedad, resulta delicado repetirlos, ya que las construcciones constitucionales se establecen en medio de un juego de represión de pasiones sociales, de una liberación del ahogó a los problemas nacionales del tiempo y de una fervorosa transformación de nuevas formas en superación de las antiguas. ${ }^{2}$

Con todo, de acuerdo con la propuesta de Hamilton y Madison, se resalta que, en vez de llamamientos frecuentes al pueblo, las apelaciones como medio de adecuación,

poderes no debían mezclarse, la concentración del poder, ejercido por muchas manos y no por una sola, constituye también la definición de un gobierno despótico. Bajo su análisis, puede que un centenar de déspotas sean tan opresores como uno solo, así sean elegidos por el pueblo. Por esa razón, la convención aprobadora del Estatuto de Gobierno adoptó como base, que los tres poderes fueran distintos y diferentes y que ninguna persona ejerciera de manera simultánea más de uno de éstos poderes. No obstante, no se estableció una barrera adecuada entre los diversos poderes. Así, los miembros del poder judicial y del ejecutivo quedaron bajo dependencia del legislativo en cuanto al sostenimiento de sus cargos. Por tanto, si el legislativo asume también el poder ejecutivo y judicial, no encuentra una oposición relevante, en ese sentido, puede otorgar a sus procedimientos la forma de ley obligando a las otras ramas. (JEFFERSON, 2017). En sentido similar, Madison analiza el caso del Estado de Pensilvania. De acuerdo con su análisis, el Consejo de Sensores, quienes tenían la labor de analizar si la Constitución garantizaba que los poderes cumplieran el deber de protectores del pueblo, o si habían asumido otros poderes diferentes a los otorgados por la consitutción. En su resultado, el Consejo evidenció una grave violación a los principios, gran parte de los contenidos legislativos habían sido promulgados sin la publicidad debida, el juicio por jurado, establecido constitucionalmente, había sido violado y el poder ejecutivo había sido usurpado (HAMILTON; MADISON; JAMES, 2018, p. 48).

${ }^{2}$ La validez del análisis de Madison puede ser visto desde la propuesta comparada del presente escrito. Véase como en Colombia, la Constitución de 1991 nació por la convergencia de tres elementos críticos. En primer lugar, el régimen del Frente Nacional de los años 70 que generó efectos negativos en términos de clientelismo, falta de representatividad y fragmentación de los partidos políticos. Un segundo elemento, correspondiente con el deterioro del orden público producto de la delincuencia común, la violencia de los grupos armados, así como el terror generado por las mafias del narcotráfico. En tercer lugar, una notoria desigualdad económica en la distribución del ingreso y los altos niveles de pobreza (ORJUELA, 2011, p. 6 8). En Brasil, al final de la década de los 70 se presentó un resurgimiento de la sociedad civil brasilera, principalmente, en términos de la ampliación de los espacios de lucha politica en pro de la libertad, la democracia y los derechos sociales. Con el fin de la dictadura se observaba el inicio de un proceso de construcción democrática y de la ciudadanía, prueba de ello, fue la creciente organización de movimientos sociales. Para el particular véase: (GABARDO, 2009).

235 • R. Opin. Jur., Fortaleza, ano 19, n. 32, p.228-266, set./dez. 2021 
¿Independencia judicial según los jueces constitucionales? un análisis conceptual a partir de las decisiones del Supremo Tribunal Federal de Brasil y de la Corte Constitucional de Colombia

prevención y corrección a las infracciones constitucionales sean ocasionales (HAMILTON; MADISON, 2018, p. 50).

Con respecto al poder judicial y su independencia, el escrito 78 del Federalista determina con cierta tranquilidad que los Tribunales no influyen sobre las armas, ni sobre el tesoro, ni dirijan la riqueza ni la fuerza de la sociedad, puesto que no puede tomar una resolución activa. De modo similar, resaltan que los mismos, a diferente del ejecutivo y del legislativo, no poseen fuerza ni voluntad, únicamente de un discernimiento que no es del todo independiente, por cuanto, en definitiva, requiere del brazo ejecutivo para el cumplimiento eficaz de sus decisiones. Por estas razones, argumentan que el poder judicial es el más débil de los tres, puesto que nunca podrá atacar con éxito ninguno de los otros poderes.

Dentro esa debilidad, podría decirse preliminarmente, que Hamilton advierte que se debe prevenir la unión del poder judicial con los otros poderes o departamentos, pues por la natural debilidad de este, puede existir una sumisión del judicial al legislativo o al ejecutivo, ya que se puede encontrar atemorizado, influido o dominado por estos otros poderes, lo que influiría en la independencia de su función. Una afirmación que para los tiempos actuales resulta trastornada, principalmente en sistemas jurídicos que no comparten la tradición del common law, pero si donde existe un consenso sobre la división y el equilibrio de los poderes (Cfr. SALGADO, 2018, p. 193).

Además de este trastorno, el problema se ha invertido, ya que lo evidente en sistemas no propios del common law, pero si comunes en el consenso referido, es el ejercicio continuo de creación de reglas, de acumulación de autoridad de interpretación de la Constitución hasta del mismo ejercicio del poder de legislar y ejecutar (VIEIRA, 2008, p. 441-464). Una realidad amparada sobre las transformaciones del nuevo constitucionalismo, que pone en riesgo el equilibrio del sistema de pesos y contrapesos, así como la garantía y la estabilidad de una sana democracia de mayorías, del pueblo.

Volviendo al análisis conceptual de la independencia judicial, El Federalista dispone que la independencia es necesaria para proteger la Constitución y los derechos individuales de la ambición y la influencia de las coyunturas especiales que se esparcen sobre el pueblo, pues constituye una salvaguardia esencial contra estos efectos. Así confió Hamilton, de una manera hoy discutible, que los que se hacen llamar amigos de la Constitución no se unirán con sus enemigos, quienes ponen en duda el principio del gobierno republicano, que reconoce al pueblo el derecho y cualquier disposición sobre la Constitución. Se dice discutible por cuanto, los que se han llamar amigos de la Constitución, se han vuelto, en muchos casos, en los enemigos de esta, lo que es aún más peligroso. 
Con todo, de acuerdo con Hamilton y su análisis en El Federalista, la independencia judicial constituye una salvaguarda fundamental para la protección de la Constitución y de los derechos individuales. La cual, es una garantía desde dos aspectos, la permanencia en el cargo de quienes ejercen la justicia y la forma en que se establece su remuneración. ${ }^{3}$

Tiempo después, Tocqueville (2019), analizando el poder judicial en los Estados Unidos y su acción sobre la sociedad política, argumentó, que aún siendo francés y reconociendo la dificultad de analizar la organización judicial en América, en los Estados Unidos el judicial es uno de los primeros poderes políticos, los magistrados no parecen nunca inmiscuirse en los asuntos públicos más allá de la casualidad, una casualidad que defiende ser renovada a diario. Qué aún parecido a los magistrados de otras naciones, están revestidos de un gran poder político.

Analiza, además, que, si bien en Francia la Constitución es una obra inmutable o reputada como tal, en Inglaterra puede cambiar sin límite porque no existe, en los Estados Unidos, los jueces deben fundamentar sus decisiones sobre la Constitución mas bien que sobre las leyes, lo que supone que no existe una inmutabilidad al estilo francés. Mas bien, forma un cuerpo independiente, que, representando la voluntad del pueblo, obliga lo mismo a los legisladores que a los ciudadanos, pero que puede ser alterado por la misma voluntad del pueblo en los términos constitucionalmente propuestos.

Implícitamente se podría argumentar, que Tocqueville al defender que el poder concedido a los tribunales norteamericanos de pronunciarse sobre la inconstitucionalidad de las leyes, forma una de las barreras más poderosas contra la tiranía de las asambleas políticas. Indica que, la autoridad independiente de los jueces está orientada a la salvaguarda de la Constitución en favor de la garantía de los derechos fundamentales.

El surgimiento de las constituciones americanas correspondió con los momentos cúspide de la Ilustración europea, lo que implicó, entre otras, una solicitud de liberación de la actuación judicial de cualquier dependencia u obstáculo sea interno o externo, y que pueda supeditar su ejercicio a elementos ajenos al derecho. Esto se elevó como el principio de independencia judicial, fundado sobre el derecho de los ciudadanos a ser juzgados

\footnotetext{
${ }^{3}$ Para Hamilton, la permanencia se defiende si se estuviera frente a una posesión de cargos en virtud de designaciones temporales, "cualquiera que sea la forma como se regulen o la persona que los haga, resultarían fatales para esa imprescindible independencia". Para ellos, es fácil comprender que "se necesitaría una firmeza poco común de parte de los jueces para que sigan cumpliendo con su deber como fieles guardianes de la Constitución, cuando las contravenciones a ella por el elgislativo hayan sido alentadas por la opinión de la mayor parte de la comunidad”. En cuanto a su remuneración, defiende que no se puede fijar sueldos permanentes a los jueces, por cuanto, deben recibir "intervalos fijos de remuneraciones que no puedan ser disminuidas durante su permanencia en las funciones”. (HAMILTON; MADISON; JAY, 2018, p. 78-79).
}

237 R. Opin. Jur., Fortaleza, ano 19, n. 32, p.228-266, set./dez. 2021 
¿Independencia judicial según los jueces constitucionales? un análisis conceptual a partir de las decisiones del Supremo Tribunal Federal de Brasil y de la Corte Constitucional de Colombia

exclusivamente desde parámetros jurídicos y desde el ordenamiento jurídico positivo o común al que se circunscriben sus actuaciones (LÖSING, 2011, p. 413-428).

De acuerdo con Lösing, el hecho de que en parte de las constituciones se declare la independencia de los jueces, no significan que realmente lo sean. A su juicio, lo que define la independencia del juez en un Estado Democrático de Derecho es su conciencia. En otras palabras, la autoestima del juez le ayuda a mantener su independencia a pesar de las presiones políticas o de la opinión pública (LÖSING, 2011, p. 423).

No obstante, a pesar de que la posición de Lösing está revestida de certeza, no se puede olvidar la volatilidad moral por la que atraviesan todos los seres humanos, inclusive los jueces, que sus decisiones no son palabra inmutable y verdadera. Por más de que en cierto periodo los jueces gocen de gran prestigio, como ocurre en Alemania, su independencia no puede supeditarse a la posición subjetiva del funcionario público designado para impartir justicia.

Por otro lado, si con ocasión de los conflictos bélicos del siglo XX, para Lösing la funcionalidad de la ley haya cambiado y el poder de los jueces haya aumentado (BACHOF, 1979, p. 172). Asimismo, que el ritmo acelerado y desmesurado de los cambios legislativos ha generado consecuencias no deseadas sobre la calidad legislativa, que los órganos de representación popular carezcan de legitimidad y confianza por parte del pueblo; la creación de un contrapeso, de un poder en condiciones de salvaguardar la Constitución y hacer cumplir los valores superiores del derecho, siendo contrarios a la posición del autor, no puede ser el juez y sus amplias facultades de control.

Si bien el juez representa un instrumento efectivo para atender la protección de garantías sociales constitucionalmente deseables, también puede darse el caso que su posición sea contraria a ideales republicanos, lo que es propio de la naturaleza humana. El juez y su independencia no puede ser un criterio subjetivo de su posición y su prestigio, su personalidad e independencia debe sujetarse y delinearse según parámetros constitucionales, fundados en la idea constituyente del pueblo a través de sus representantes.

Teniendo en cuenta esas consideraciones teóricas e históricas, fundamentadas a partir del equilibrio e independencia de los poderes, de la objetividad que debe revestir la materialización de los principios, entre otros factores que identifican la autonomía e independencia del juez en un Estado Social de Derecho, resulta interesante como quienes son declarados "guardianes de la Constitución", aún representando la misma autoridad judicial, definen, naturalizan y caracterizan la independencia judicial. 


\section{LA INDEPENDENCIA JUDICIAL SEGÚN EL SUPREMO TRIBUNAL FEDERAL DE BRASIL Y LA CORTE CONSTITUCIONAL DE COLOMBIA}

Previo al análisis de las decisiones de ambos tribunales constitucionales es pertinente considerar tres aspectos sobre la investigación. La primera, relacionada con el levantamiento de información, se gestionó a través de los sitios web de investigación jurisprudencial habilitado por los tribunales, y se delimitó a la búsqueda de las siguientes categorías: para el caso colombiano, el de independencia judicial. Mientras que, para el caso brasilero, las categorías empleadas fueron: independencia judicial, principio de separación de poderes, independencia del poder judicial, imparcialidad del poder judicial, imparcialidad de los jueces. La pluralidad de este último obedece al entendimiento que se le ha brindado por el Supremo Tribunal Federal y a la cantidad limitada de decisiones que desarrollaban de forma literal la expresión "independencia judicial".

La segunda, de manera consecuente, una vez depuradas las decisiones, se seleccionaron 24 sentencias de la Corte Constitucional y 12 del Supremo Tribunal federal. Esa selección correspondió con las propuestas más próximas a un concepto literal y explicativo de la independencia judicial. Por otro lado, el período de tiempo seleccionado para la investigación correspondió: para el caso colombiano, desde 1992 hasta el 2019, periodo de funcionamiento vigente de la Corte Constitucional, mientras que, para el caso brasilero, desde la fecha dispuesta, habilitada y publicada por la página web del Supremo Tribunal Federal. Asimismo, el análisis de la jurisprudencia investigada y seleccionada para el presente trabajo se presenta a través de un diálogo entre ambos tribunales, en cada uno los aspectos propuestos para el estudio: presupuestos, concepto, naturaleza jurídica, características, sentidos, facetas y tipologías de la independencia judicial.

Finalmente, de acuerdo con los resultados de la investigación, el trabajo difiere de los estudios comunes estructurados a partir de un análisis jurisprudencial, en la medida que no reconoce un leading case. No obstante, no es excluyente en dar relevancia a algunas decisiones que brindaron impacto y desarrollo a la idea de la independencia judicial.

\subsection{PRESUPUESTOS, CONCEPTO Y NATURALEZA JURÍDICA}

La independencia judicial como presupuesto del Estado Social de Derecho encuentra soporte en contenidos constitucionales y legales. En Colombia, los artículos 228 y 230 de la Constitución de 1991 determinan que las decisiones de la Administración de Justicia, en el ejercicio de la función pública, son independientes y sometidas al imperio de 
¿Independencia judicial según los jueces constitucionales? un análisis conceptual a partir de las decisiones del Supremo Tribunal Federal de Brasil y de la Corte Constitucional de Colombia

la ley. En desarrollo de los mandatos constitucionales, la Ley Estatutaria de la Administración de Justicia en su artículo $5^{\circ}$ reitera la independencia del poder judicial tanto de los mismos jueces jerárquicamente superiores como de otras autoridades legislativas o administrativas. A su vez, la Constitución brasilera de 1988, consagró en el artículo $2^{\circ}$, que los poderes de la Unión son independientes y armónicos entre sí. ${ }^{4}$

Invocando estas disposiciones, los tribunales constitucionales, de manera particular, el Supremo Tribunal Federal y la Corte Constitucional, han dado un contenido disímil, no solo desde el punto de vista teórico, desarrollado en sus providencias, sino también desde su materialización, haciendo referencia a algunos casos donde es evidente una aplicación indebida y/o genérica de la independencia judicial.

Antes de dar contenido al entendimiento de los tribunales constitucionales, resulta interesante preguntarse ¿Quién debe definir realmente qué es la independencia judicial? ¿la Constitución, la ley o los mismos jueces? ¿la independencia judicial tiene un fundamento? ¿Cuál es la naturaleza jurídica de la independencia judicial? ¿Cómo y bajo qué parámetros se puede caracterizar la independencia judicial? Son estos y otros interrogantes sobre lo que se desarrolla el presente capítulo y se pretende encaminar el artículo.

De acuerdo con el fundamento que le da soporte, la Corte Constitucional ha determinado de manera uniforme en la jurisprudencia seleccionada que la independencia judicial se sustenta en el principio de legalidad, el sometimiento del juez al imperio de la ley. Con base en ese presupuesto, el juez constitucional debe tener en cuenta como premisa las potestades y prerrogativas otorgadas bajo su autoridad en la parte orgánica de la Constitución. Asimismo, a partir de allí, su independencia se erige como una garantía institucional de la función pública, orientado al cumplimiento de los fines del Estado, a través de la garantía efectiva de los principios, derechos y deberes consagrados en la Constitución. $^{5}$

Por su parte, para el Supremo Tribunal Federal, la independencia judicial encuentra soporte en la Constitución. No sólo en la disposición constitucional que hace referencia a la independencia y armonía de los poderes de la Unión, sino también en la cláusula pétrea consagrada en el artículo $60, \S 4^{\circ}$, III, según la cual, no puede ser objeto de reforma constitucional la separación de los poderes. ${ }^{6}$

\footnotetext{
${ }^{4}$ La Constitución de la República Federativa de Brasil dispone literalmente: "Art. $2^{\circ}$ São Poderes da União, independentes e harmônicos entre si, o Legislativo, o Executivo e o Judiciário". (BRASIL, 1988, online).

${ }^{5}$ COLOMBIA. Corte Constitucional. Sentencia de Constitucionalidad 836 de 2001. Relator: M.P. Rodrigo Escobar Gil, Bogotá D.C, 09 de agosto de 2001.

${ }^{6}$ BRASIL. Supremo Tribunal Federal. Medida cautelar na Ação Direta de Inconstitucionalidade no 5316, Distrito Federal. Requerente: Associação dos Magistrados Brasileiros - AMB. Relator: Min. Luiz Fux. Brasília, DF, 21 de mayo de 2015. Brasília, 06 out. 2015.
} 
Teniendo en cuenta esos pilares, el Supremo Tribunal Federal ha definido la independencia judicial en el Estado Democrático de Derecho, como una condición indispensable para la preservación de las libertades fundamentales. De ahí que, si el juez no tiene libertad para decidir, y si no dispone de cierto grado de independencia para dirimir los conflictos de intereses, incluso, aquellos establecidos en función de los comportamientos abusivos del poder público, transformaría en un sentido negativo, abstracto e inútil el entendimiento de la libertad de los ciudadanos. ${ }^{7}$

El Supremo Tribunal Federal ha entendido que la independencia judicial es una garantía de los ciudadanos para asegurar juicios libres de presiones, fundamentados en derecho. De ese modo, el juez es libre e independiente cuando juzga de acuerdo con la libre convicción, con sujeción al derecho. ${ }^{8}$

Por su parte, la Corte Constitucional ha dado mayor amplitud y desarrollo a la definición de la independencia judicial en sus providencias. De acuerdo con una perspectiva axiológica, la independencia judicial equivale a imparcialidad, lo que implica que el juez tiene la carga y el deber de garantizar a la sociedad que sus decisiones sean objetivas, con sujeción al principio de igualdad y de legalidad, ${ }^{9}$ al reconocimiento de los derechos constitucionales y la aplicación del derecho constitucional. ${ }^{10}$ Una garantía manifiesta al momento de aplicar congruentemente la Constitución y la ley, de adecuar las normas jurídicas pertinentes al caso concreto, de determinar su forma de aplicación, la manera de interpretación y los efectos que de ella se derivan, ${ }^{11}$ siempre con sujeción a los contenidos, postulados, principios y derechos constitucionales. ${ }^{12}$

${ }^{7}$ BRASIL. Supremo Tribunal Federal. Acórdão no 2699-9. Relator: Celso de Mello. Brasília, DF, 12 de março de 2019. Quest. Ord. em Inquérito 2.699-9 Distrito Federal. Brasília, 08 mayo 2009.

${ }^{8}$ BRASIL. Supremo Tribunal Federal. Ação Direta de Inconstitucionalidade no 4414. Relator: Ministro Luiz Fux. Brasil, Alagoas, 31 de maio de 2012. Brasília. De igual modo, BRASIL. Supremo Tribunal Federal. Ação Direta de Inconstitucionalidade no 98-5, Mato Grosso. Requerente: Procurador-Geral da República. Relator: Min. Sepúlveda Pertence. Supremo Tribunal Federal. Brasília, DF, 07 de agosto de 1997. Brasília, 31 out. 1997; BRASIL. Supremo Tribunal Federal. Ação Direta de Inconstitucionalidade n 183-3, Mato Grosso. Relator: Min. Sepúlveda Pertence; BRASIL. Supremo Tribunal Federal. BRASIL. Mandado de Segurança no 30819. Relator: Min. Luiz Fux. Brasília, DF, 22 de abril de 2015. Brasília, 28 abr. 2015.

${ }^{9}$ COLOMBIA. Corte Constitucional. Sentencia de Constitucionalidad 1643 de 2000. Relator (encargado): M.P. Jairo Charry Rivas, Bogotá D.C, 29 de noviembre de 2000. Reiterada también en: Sentencia de Tutela 593 de 2002, Sentencia de Constitucionalidad 1024 de 2002, Constitucionalidad 288 de 2012, Constitucionalidad 870 de 2014, Constitucionalidad 112 de 2019.

${ }^{10}$ COLOMBIA. Corte Constitucional. Sentencia de Tutela 593 de 2002. Relator: M.P. Manuel José Cepeda Espinosa, Bogotá D.C, 01 de agosto de 2002.

${ }^{11}$ COLOMBIA, Corte Constitucional. Sentencia de Unificación 539 de 2012. Relator: M.P. Luis Ernesto Vargas Silva, Bogotá D.C, 12 de julio de 2012. Del mismo sentido, Sentencia de Tutela 330 de 2005.

${ }^{12}$ COLOMBIA. Corte Constitucional. Sentencia de Tutela 1165 de 2003. Relator: M.P. Rodrigo Escobar Gil, Bogotá D.C, 4 de diciembre de 2003. De manera similar: COLOMBIA. Corte Constitucional.

241 R. Opin. Jur., Fortaleza, ano 19, n. 32, p.228-266, set./dez. 2021 
¿Independencia judicial según los jueces constitucionales? un análisis conceptual a partir de las decisiones del Supremo Tribunal Federal de Brasil y de la Corte Constitucional de Colombia

En otras palabras, la independencia judicial implica que, para el ejercicio adecuado de la función pública, los jueces no han de tener ningún tipo de dependencia con relación a las otras ramas del poder público. ${ }^{13}$ Así tampoco, presión, insinuación, recomendación, exigencia, determinación o diferentes consejos sobre sus decisiones por parte de los otros órganos de poder, inclusive de la misma rama judicial. ${ }^{14}$

De igual modo, ambos tribunales constitucionales han enlistado o propuesto una serie de condiciones no taxativas, a partir de las cuales se puede garantizar la independencia judicial frente a los poderes constituidos dentro de la organización política, los demás actores que integran el poder judicial, y otro tipo de actores como los medios de comunicación, los grupos de presión y el poder económico.

Estas condiciones pueden ser analizadas a partir de una perspectiva subjetiva y una objetiva. La Corte Constitucional, por ejemplo, desde el plano objetivo, propone y reafirma la existencia de procesos abiertos, transparentes, participativos y con posibilidad de escrutinio por la sociedad, garantías para el régimen disciplinario de los jueces, -visto este último, como un instrumento de no retaliación e intimidación en su ejercicio-, hasta la existencia de un cuerpo robusto en la conducción de la Administración de la Justicia dentro del poder judicial y separado de los otros poderes. ${ }^{15}$

Desde una perspectiva subjetiva, la Corte Constitucional ha determinado que la garantía de la independencia del juez depende de la libertad para el ejercicio de su función pública. En ese sentido puede ser estructural, si en sí mismo recae la idea de crear mecanismos de protección formal que puedan ser invocados si ve amenazada su independencia. O cultural, dotándose de instrumentos de garantía frente a valores informales coyunturales y cualquier tipo de tradición inmersa en la sociedad, tomando conciencia de su acción social. ${ }^{16}$

Sentencia de Tutela 284 de 2006. Relator: M.P: Clara Inés Vargas Hernández, Bogotá D.C, 5 de abril de 2006. Y; COLOMBIA. Corte Constitucional. Sentencia de Tutela 107 de 2014. Relator: M.P. Luis Ernesto Vargas Silva, Bogotá D.C, 28 de febrero de 2014.

${ }^{13}$ COLOMBIA. Corte Constitucional. Sentencia de Constitucionalidad 1024 de 2002. Relator: M.P. Alfredo Beltrán Sierra. Bogotá D.C, 26 de noviembre de 2002.

${ }^{14}$ COLOMBIA. Corte Constitucional. Sentencia de Constitucionalidad 540 de 2011. Relator: M.P. Jorge Ignacio Pretelt Chaljub, Bogotá D.C, 6 de julio de 2011. En sentido similar, resaltando la autonomía e independencia judicial como la garantía de los derechos y el instrumento eficaz para la resolución pacífica de las controversias: COLOMBIA, Corte Constitucional. Sentencia de Constitucionalidad 288 de 2012. Relator: M.P. Luis Ernesto Vargas Silva, Bogotá D.C, 18 de abril de 2012.

${ }^{15}$ COLOMBIA. Corte Constitucional. Sentencia de Constitucionalidad 373 de 2016. Relator: M.P. Alejandro Linares Cantillo y Gabriel Eduardo Mendoza Martello, Bogotá D.C, 13 de julio de 2016.

${ }^{16}$ COLOMBIA. Corte Constitucional. Sentencia de Constitucionalidad C- 565 de 2017, Relatora: MP. Diana Fajardo Rivera, Bogotá D.C, 8 de septiembre de 2017. 
A su vez, el Supremo Tribunal Federal determina para las condiciones subjetivas que, en el proceso de construcción interno del juez, éstos no sean apenas formales, lo que implican que cumplan con efectividad su función pública a través de una recta conciencia y una grandeza de espíritu, desvistiéndose de preconceptos corporativos o posturas irracionales para la construcción de un juicio sereno orientado hacia el interés público. ${ }^{17}$

Desde el punto de vista objetivo, el Supremo Tribunal Federal en varias de sus providencias, propone la existencia de una colegiatura judicial que asegure la independencia de forma mas eficaz. Si la decisión es tomada de forma colegiada, disminuye el riesgo de imputación a una persona única, se mitigan los riegos y se torna difusa la responsabilidad, dando, a su juicio, mayor aceptación y credibilidad dentro de la sociedad. ${ }^{18}$

Bajo las mismas condiciones, diferente a lo que sucede en el ordenamiento jurídico colombiano, el Supremo Tribunal Federal no defiende la idea de un cuerpo robusto de carácter administrativo en la administración de los jueces y tribunales. A su juicio, es ilusoria la facultad de distinguir funciones judiciales y administrativas, no se puede admitir la injerencia de otros órganos en su actuación. De acuerdo con su postura, admitirlo sería alterar el ejercicio de la democracia y el principio de separación de poderes. ${ }^{19}$

Otra diferencia se sienta sobre la defensa de que los jueces sean vitalicios como garantía de la independencia judicial, a su juicio, si bien esta garantía puede ser relativa cuando se cumplen las circunstancias para la pérdida de su investidura o el cumplimiento de la edad y la jubilación, ${ }^{20}$ el hecho de ser vitalicios representa la salvaguarda permanente de la justicia cuando ejerce su función. ${ }^{21}$

${ }^{17}$ BRASIL. Supremo Tribunal Federal. Ação Direta de Inconstitucionalidade no 3367-1, Distrito Federal. Requerente: Associação dos Magistrados Brasileiros - AMB. Relator: Min. Cezar Peluso, DF, 13 de abril de 2005. Brasília, 22 setembro de 2006.

${ }^{18}$ BRASIL. Supremo Tribunal Federal. Ação Direta de Inconstitucionalidade no 4414. Relator: Ministro Luiz Fux. Brasil, Alagoas, 31 de maio de 2012. Brasília.

${ }^{19}$ BRASIL. Supremo Tribunal Federal. Ação Direta de Inconstitucionalidade no 135-3, Paraíba. Requerente: Associação dos Magistrados Brasileiros -AMB. Relator: Min. Octavio Galloti. Brasília, DF, 21 de novembro de 1996. Brasília, 15 agosto 1997. En otra decisión, a propósito del análisis sobre la constitucionalidad de la creación del Consejo Nacional de Justicia, el SUPREMO TRIBUNAL FEDERAL se rehúsa en la mayoría de sus decisiones a su reconocimiento, optando por un autogobierno de los mismos jueces. Para el particular véase: BRASIL. Supremo Tribunal Federal. Ação Direta de Inconstitucionalidade no 3367-1, Distrito Federal. Requerente: Associação dos Magistrados Brasileiros - AMB. Relator: Min. Cezar Peluso, DF, 13 de abril de 2005. Brasília, 22 setembro de 2006.

${ }^{20}$ Se refiere en português a la "aposentadoria compulsória".

${ }^{21}$ BRASIL. Supremo Tribunal Federal. Ação Direta de Inconstitucionalidade no 98-5, Mato Grosso. Requerente: Procurador-Geral da República. Relator: Min. Sepúlveda Pertence. Supremo Tribunal Federal. Brasília, DF, 07 de agosto de 1997. Brasília, 31 out. 1997. Em el mismo sentido: BRASIL. Supremo Tribunal Federal. Ação Direta de Inconstitucionalidade no 183-3, Mato Grosso. Relator: Min. Sepúlveda Pertence. Caso contrario en Colombia, como se va a ver al analizar las dimensiones:

243 - R. Opin. Jur., Fortaleza, ano 19, n. 32, p.228-266, set./dez. 2021 
¿Independencia judicial según los jueces constitucionales? un análisis conceptual a partir de las decisiones del Supremo Tribunal Federal de Brasil y de la Corte Constitucional de Colombia

Con relación a su naturaleza jurídica, existe unanimidad entre las decisiones seleccionadas de la Corte Constitucional y el Supremo Tribunal Federal que la independencia judicial, así como la seguridad jurídica, es un principio fundante, componente medular del Estado democrático. ${ }^{22}$ Para la Corte Constitucional es un principio relacional, de argumentación y decisión, por cuanto se utiliza para caracterizar las interacciones del poder judicial con otros poderes, siembre bajo la ausencia de cualquier tipo de influencia en su aplicación. ${ }^{23}$

Para el Supremo Tribunal Federal el principio de la independencia judicial está asociado al dogma intangible de la separación de poderes, a partir del cual se desprende la autonomía administrativa, financiera y presupuestaria. ${ }^{24}$ De igual modo, además de principio, el Supremo Tribunal Federal le ha otorgado la nominación de valor político supremo, así como de un derecho del magistrado de proferir decisiones bajo el amparo de la libertad. Lo que analizando la decisión dada por el Supremo Tribunal Federal, es un derecho y una garantía no sólo del juez sino también de los ciudadanos. ${ }^{25}$

COLOMBIA. Corte Constitucional. Sentencia de Constitucionalidad C- 565 de 2017, Relatora: MP. Diana Fajardo Rivera, Bogotá D.C, 8 de septiembre de 2017. Esta posición que va en contravía de los nombramientos periódicos también es defendible por el Hamilton en El Federalista 78, ql indicar que resultan fatalaes para la independencia judicial, porque surgiría una propensión exagerada a pensar en la popularidad, por lo que a su razón, ven imposible confiar en que no se tenga en cuenta la Constitución y la ley.

${ }^{22}$ COLOMBIA, Corte Constitucional. Sentencia de Tutela 096 de 2003. Relator: M.P. Jaime Araujo Rentería, Bogotá D.C, 20 de octubre de 2003. Para el caso de Brasil: BRASIL. Supremo Tribunal Federal. BRASIL. Mandado de Segurança no 30819. Relator: Min. Luiz Fux. Brasília, DF, 22 de abril de 2015. Brasília, 28 abr. 2015. Así también: BRASIL. Supremo Tribunal Federal. Ação Direta de Inconstitucionalidade no 1.578-8, Alagoas. Requerente: Associação dos Magistrados Brasileiros - AMB. Relator: Min. Carmen Lúcia. Brasília, DF, 04 de março de 2009. Brasília, 03 de abril de 2009.

${ }^{23}$ La ya citada: COLOMBIA. Corte Constitucional. Sentencia de Constitucionalidad C- 565 de 2017. Relatora: MP. Diana Fajardo Rivera, Bogotá D.C, 8 de septiembre de 2017, sobre la cual se anliza la constitucionalidad de aspectos relacionados con la Justicia Especial para la Paz, representa una sentencia fundamental en el desarrollo conceptual de la independencia judicial.

${ }^{24}$ BRASIL. Supremo Tribunal Federal. Ação Direta de Inconstitucionalidade no 98-5, Mato Grosso. Requerente: Procurador-Geral da República. Relator: Min. Sepúlveda Pertence. Brasília, DF, 07 de agosto de 1997. Brasília, 31 out. 1997. Em el mismo sentido: BRASIL. Supremo Tribunal Federal. Ação Direta de Inconstitucionalidade no 183-3, Mato Grosso. Relator: Min. Sepúlveda Pertence. Brasília, DF, 07 de agosto de 1997. Brasília, 31 outubro de 1997.

${ }^{25}$ BRASIL. Supremo Tribunal Federal. Ação Direta de Inconstitucionalidade no 3367-1, Distrito Federal. Requerente: Associação dos Magistrados Brasileiros - AMB. Relator: Min. Cezar Peluso, DF, 13 de abril de 2005. Brasília, 22 setembro de 2006; ${ }^{25}$ BRASIL. Supremo Tribunal Federal. Acórdão no 2699-9. Relator: Celso de Mello. Brasília, DF, 12 de março de 2019. Quest. Ord. em Inquérito 2.699-9. Brasília, 08 mayo 2009. 


\subsection{CARACTERÍSTICAS, TIPOLOGÍAS, SENTIDOS Y FACETAS DE LA INDEPENDENCIA JUDICIAL}

Sobre sus características, las posiciones son variadas, no sólo por las diferentes atribuciones que se le atribuyen al principio de la independencia judicial, sino porque al tener un contenido amplio, permite inserir cualquier tipo de soporte relacionado con el mismo. Vale la pena hacer referencia a algunas carácteristicas comunes en las decisiones seleccionadas.

En primer lugar, la independencia judicial es una expresión del principio de separación de poderes y el pilar de la Administración de Justicia, posición que es uniforme en ambos tribunales. ${ }^{26}$ Asimismo, la Corte Constitucional y el Supremo Tribunal Federal han coincidido en que el ejercicio de la independencia judicial, la competencia asignada para interpretar y aplicar las normas jurídicas no es absoluta. Al ser reglada su función pública, está limitada por el respeto y la corrección dentro del sistema jurídico, los derechos, deberes y principios constitucionales, inclusive, para el caso colombiano, la jurisprudencia de unificación dictada por las tres altas cortes y la jurisprudencia de la Corte Constitucional. ${ }^{27}$

No obstante, algunas decisiones de la Corte Constitucional han defendido que es un principio absoluto. ${ }^{28}$ Su fundamento radica en la imparcialidad del ejercicio de su función y la amplia libertad que tiene frente al caso en concreto. Esta última postura no ha tenido

\footnotetext{
${ }^{26}$ Para el caso colombiano: COLOMBIA, Corte Constitucional. Sentencia de Constitucionalidad 288 de 2012. Relator: M.P. Luis Ernesto Vargas Silva, Bogotá D.C, 18 de abril de 2012. Para el caso brasilero basta analizar las decisiones ya referenciadas sobre el principio de separación de pdoeres.

${ }^{27}$ Véase, por ejemplo: COLOMBIA. Corte Constitucional. Sentencia de Tutela 1165 de 2003. Relator: M.P. Rodrigo Escobar Gil, Bogotá D.C, 4 de diciembre de 2003, COLOMBIA. Corte Constitucional. Sentencia de Tutela 107 de 2014. Relator: M.P. Luis Ernesto Vargas Silva, Bogotá D.C, 28 de febrero de 2014. Con relación a los límites: COLOMBIA. Corte Constitucional. Sentencia de Tutela 302 de 2006. Relator: M.P. Rodrigo Escobar Gil, Bogotá D.C, 7 de abril de 2006, COLOMBIA, Corte Constitucional. Sentencia de Tutela 1031 de 2001. Relator: M.P. Eduardo Montealegre Lynett, Bogotá D.C, 27 de septiembre de 2001, COLOMBIA. Corte Constitucional. Sentencia de Tutela 191 de 2009. Relator: M.P. Luis Ernesto Vargas Silva, Bogotá D.C, 20 de marzo de 2009. Ya para el caso de Brasil que reafirma que el principio no es absoluto, la ya referenciada: BRASIL. Supremo Tribunal Federal. Ação Direta de Inconstitucionalidade ${ }^{\circ}$ 3367-1, Distrito Federal. Requerente: Associação dos Magistrados Brasileiros - AMB. Relator: Min. Cezar Peluso, DF, 13 de abril de 2005. Brasília, 22 setembro de 2006.

${ }^{28}$ Véase: COLOMBIA, Corte Constitucional. Sentencia de Constitucionalidad 288 de 2012. Relator: M.P. Luis Ernesto Vargas Silva, Bogotá D.C, 18 de abril de 2012. Así también; COLOMBIA. Corte Constitucional. Sentencia de Constitucionalidad 037 de 1996. Relator: M.P. Vladimiro Naranjo Mesa, Bogotá D.C, 5 de febrero de 1996.
}

245 R. Opin. Jur., Fortaleza, ano 19, n. 32, p.228-266, set./dez. 2021 
¿Independencia judicial según los jueces constitucionales? un análisis conceptual a partir de las decisiones del Supremo Tribunal Federal de Brasil y de la Corte Constitucional de Colombia

impacto con relación a aquellas que reiteran el no absolutismo de la independencia judicial.

En segundo lugar, el principio de independencia judicial promueve la armonía con los principios del debido proceso legal, refuerza o materializa la legalidad al actuar dentro de los rangos establecidos por la Constitución y por las leyes, así como constituye un elemento fundamental del debido proceso. ${ }^{29}$

En tercer lugar, la independencia judicial es incompatible con mecanismos que permitan controles recíprocos entre las diferentes autoridades, mismo si las invita a actuar bajo una labor de coordinación con la finalidad de alcanzar los fines del Estado, en últimas, la colaboración armónica no supone un control sobre los demás poderes. ${ }^{30}$

No obstante, el Supremo Tribunal Federal ha tomado una posición contraria, en el sentido de que bajo el entendimiento de la independencia judicial, el poder judicial es por excelencia un poder de control de los demás poderes, sobre todo en términos de unidad e universalidad, preservación de los derechos fundamentales y de las consideraciones democráticas. ${ }^{31}$ Asunto que bajo consideración preliminar resulta peligroso, por cuanto la garantía de los derechos es una competencia tripartita, por más independiente, no hay poder público superior a otro. Por lo menos, así no lo establece la Constitución.

Esa preocupación se refuerza aún mas cuando el Supremo Tribunal Federal indica que, si bien el juez es independiente cuando juzga de acuerdo con la libre convicción, el fundamento en derecho, el conjunto de pruebas y su apreciación sin presiones externas,

${ }^{29}$ Para el caso colombiano: COLOMBIA. Corte Constitucional. Sentencia de Tutela 096 de 2003. Relator: M.P. Jaime Araujo Rentería, Bogotá D.C, 20 de octubre de 2003, COLOMBIA. Corte Constitucional. Sentencia de Constitucionalidad 881 de 2011. Relator: M.P: Luis Ernesto Vargas Silva, Bogotá D.C, 23 de noviembre de 2011, COLOMBIA. Corte Constitucional. Auto 169 de 2009. Relator: M.P: Luis Ernesto Vargas Silva, Bogotá D.C, 29 de abril de 2009. Para el caso brasilero: BRASIL. Supremo Tribunal Federal. Medida cautelar na Ação Direta de Inconstitucionalidade no 5.104, Distrito Federal. Requerente: Procurador-Geral da República. Min. Roberto Barroso. Brasília, DF, 21 de maio de 2014. Brasília, 30 outubro 2014.

${ }^{30}$ COLOMBIA. Corte Constitucional. Sentencia de Constitucionalidad 870 de 2014. Relator: M.P. Luis Guillermo Guerrero Pérez, Bogotá D.C, 13 de noviembre de 2014; COLOMBIA. Corte Constitucional. Sentencia de Constitucionalidad C-971 de 2004. Relator: M.P. Manuel José Cepeda Espinosa, Bogotá D.C, 7 de octubre de 2004.

${ }^{31}$ BRASIL. Supremo Tribunal Federal. Ação Direta de Inconstitucionalidade no 98-5, Mato Grosso. Requerente: Procurador-Geral da República. Relator: Min. Sepúlveda Pertence. Brasília, DF, 07 de agosto de 1997. Brasília, 31 out. 1997. Em el mismo sentido: BRASIL. Supremo Tribunal Federal. Ação Direta de Inconstitucionalidade no 183-3, Mato Grosso. Relator: Min. Sepúlveda Pertence. Brasília, DF, 07 de agosto de 1997. Brasília, 31 outubro de 1997; BRASIL. Supremo Tribunal Federal. Acórdão no 2699-9. Relator: Celso de Mello. Brasília, DF, 12 de março de 2019. Quest. Ord. em Inquérito 2.699-9 Distrito Federal. Brasília, 08 mayo 2009. 
debe ser garantizada en todas las causas bajo la ley y la Constitución. ${ }^{32}$ Cabe entonces afirmar que, si de acuerdo con el Supremo Tribunal Federal la ley es la que determina hasta cuándo y como debe ser la independencia, no hay referencia normativa constitucional o legal que ampare la superioridad del poder judicial.

En cuarto lugar, la independencia judicial constituye un límite al poder de reforma (Cfr. SALGADO, 2012). No obstante, para la Corte Constitucional, a pesar del nivel de dificultad que supone una reforma constitucional que involucre la consideración del principio, debe atender a criterios indicativos para determinar si los diseños institucionales propuestos van en contravía del principio. ${ }^{33}$ Estos criterios indicativos han sido referenciados en párrafos anteriores, como garantías para la independencia judicial.

Finalmente, además de ser un factor esencial para el ejercicio de la función pública, de estar reconocido internacionalmente, la Corte Constitucional le ha atribuido una cualidad a la independencia judicial como garantía de estabilidad del sistema político, puesto que constituye un instrumento de orientación del comportamiento de los detentores del poder, conforme a las reglas básicas de la estructura de la sociedad. ${ }^{34}$

Una vez ahondado sobre los fundamentos, una posible definición, la naturaleza jurídica y algunas características relevantes del principio de la independencia judicial. La Corte Constitucional ha elaborado una tipología o ha determinado ciertos, sentidos o facetas del principio.

De acuerdo con su jurisprudencia, el juez es independiente en un doble sentido, no solo sobre la idea de que el poder judicial no está sometido a la consideración o anuencia de los otros poderes, sino también, que al fallar está atado únicamente al imperio de la ley,

\footnotetext{
${ }^{32}$ Sobre esa incongruencia manifiesta en: BRASIL. Supremo Tribunal Federal. Ação Direta de Inconstitucionalidade no 4414. Relator: Ministro Luiz Fux. Brasil, Alagoas, 31 de maio de 2012. Brasília. Para el caso Colombiano también há sido manifesta en la ya referenciada, COLOMBIA. Corte Constitucional. Sentencia de Constitucionalidad C- 565 de 2017, Relatora: MP. Diana Fajardo Rivera, Bogotá D.C, 8 de septiembre de 2017.

${ }^{33}$ COLOMBIA. Corte Constitucional. Sentencia de Constitucionalidad 373 de 2016. Relator: M.P. Alejandro Linares Cantillo y Gabriel Eduardo Mendoza Martello, Bogotá D.C, 13 de julio de 2016.

${ }^{34}$ Esta característica es igualmente incongruente con la idea de la separación de los poderes defendida por ambos tribunales. Con ocasión del análisis sobre las excepcionalidades de una transición sobre el final del conflicto armado interno en Colombia, el Tribunal Constitucional, como "guardián de la Constitución" se ha atribuido la obligación de estabilidad de la estructura política, aunque aducen siempre fundamentar sus decisiones en razones prudentes de costo-beneficio, parte de los ministros o magistrados han criticado la dependencia política de la decisión, tal es el caso del salvamento de voto la magistrada Gloria Stella Ortiz Delgado a la sentencia relevante COLOMBIA. Corte Constitucional. Sentencia de Constitucionalidad C- 565 de 2017, Relatora: MP. Diana Fajardo Rivera, Bogotá D.C, 8 de septiembre de 2017.
}

247 R. Opin. Jur., Fortaleza, ano 19, n. 32, p.228-266, set./dez. 2021 
¿Independencia judicial según los jueces constitucionales? un análisis conceptual a partir de las decisiones del Supremo Tribunal Federal de Brasil y de la Corte Constitucional de Colombia

entendida esta en un sentido material. ${ }^{35}$

Asimismo, otorga una doble dimensión al principio. ${ }^{36}$ La independencia judicial es positiva al considerar los criterios de interpretación para el ejercicio de la función y buscar garantizar la aplicación del derecho y sus fuentes. Es decir, la independencia como un principio de argumentación y decisión. Por otro lado, es negativa, cuando se opta por la necesidad de evitar distintas presiones, coerciones o atentados contra la lealtad judicial.

Esta última dimensión adquiere una connotación personal e institucional. Personal, al evitar que terceros, inclusive las otras ramas del poder, influencien directa o indirectamente la manera en que se cumple la función. Para lo cuál se hace necesario la fijación de periodos fijos de ejercicio, contrario a lo que sucede en Brasil. Asimismo, se establezcan salarios estables y dignos, se garantice transparencia en la carrera judicial y se determine claridad en el marco legal de la potestad sancionadora disciplinaria que sobre ellos recae. Por su parte, es institucional al buscar proteger la independencia de la inferencia de los otros poderes públicos.

A partir de los sentidos o dimensiones dadas, la Corte Constitucional determinó unas tipologías de independencia judicial, atendiendo al nivel de protección de la autonomía y la forma en que se proyecta frente a los otros órganos de poder. En ese sentido distingue entre independencia externa e interna. ${ }^{37}$

Por independencia externa se entiende frente a las funciones judiciales, donde el juez tiene una garantía absoluta y plena de su función. A su vez, frente a las funciones administrativas, lo que contrario a lo que defiende el Supremo Tribunal Federal, tiene una protección relativa o moderada, por cuanto el tribunal colombiano defiende y opta por la existencia de un cuerpo robusto y colegiado, dentro del poder judicial, independiente de las otras ramas del poder, que a su juicio, no amenaza la separación de los poderes.

Por independencia interna, también frente a funciones administrativas, aplica una tutela relativa, al destacar la colaboración armónica sobre los otros poderes. No obstante, frente a las funciones judiciales, reitera el amparo absoluto, en un sentido jerárquico.

Finalmente, cabe destacar las facetas otorgadas por la jurisprudencia colombiana a la independencia judicial. Bajo su juicio, el principio se manifiesta en primer lugar, en la

${ }^{35}$ COLOMBIA. Corte Constitucional. Sentencia de Constitucionalidad 888 de 2004. Relator: M.P: Clara Inés Vargas Hernández, Bogotá D.C, 14 de septiembre de 2004.

${ }^{36}$ COLOMBIA. Corte Constitucional. Sentencia de Constitucionalidad C- 565 de 2017, Relatora: MP. Diana Fajardo Rivera, Bogotá D.C, 8 de septiembre de 2017.

${ }^{37}$ COLOMBIA. Corte Constitucional. Sentencia de Constitucionalidad 285 de 2016. Relator: M.P. Luis Guillermo Guerrero Pérez, Bogotá D.C, 1 de junio de 2016. Reiterado en: COLOMBIA. Corte Constitucional. Sentencia de Tutela 450 de 2018. Relator: M.P. Luis Guillermo Guerrero Pérez, Bogotá D.C, 19 de noviembre de 2018. 
imparcialidad, entendida como la desvinculación del juez frente a las partes, con un alcance absoluto e incondicional. En segundo lugar en una autonomía funcional, bajo el entendido de tener libertad frente a los otros jueces, limitado por los mecanismos de defensa y contradicción, propios de las garantías procesales. En tercer lugar, una autonomía orgánica o insularidad política, desde el ya reiterado principio de la separación de los poderes. No obstante, éste último, es de carácter relativo al permitir intervenir a la ciudadanía en la consideración sobre los casos con relevancia constitucional que son objeto de decisión. ${ }^{38}$

Con todo, hasta ahora es legible entender cómo se han transformado las posiciones teóricas clásicas sobre el constitucionalismo y el entendimiento del principio de la independencia de los jueces. Sin embargo, la consideración sobre los fundamentos de su independencia, el destinatario real de la misma ¿para quién? y más aún, el soporte o la forma sobre el cual se invoca ¿Qué? ¿Cómo?, es lo que ha sido objeto de olvido por parte de ambos tribunales, lo que ha llevado a un ejercicio "sobreautónomo", hasta quizá solipsista de la función pública de administrar justicia. En diversos casos, redactando una Constitución o normas constitucionales para ellos y según ellos, si, según los jueces constitucionales.

\section{4 ¿JUECES INDEPENDIENTES SEGÚN QUIÉN? ¿CÓMO? ¿PARA QUIÉN? LA INDEPENDENCIA JUDICIAL Y LA ACTUACIÓN DE LOS TRIBUNALES CONSTITUCIONALES EN TIEMPOS ACTUALES}

Teniendo en cuenta los conceptos, características, dimensiones, naturaleza y tipologías de la independencia judicial, a partir de la interpretación del Supremo Tribunal Federal y la Corte Constitucional, así como los presupuestos históricos y teóricos sobre los cuáles se han inspirado algunos de los ideales democráticos del rol del juez, es necesario advertir que más allá de ser una garantía para los ciudadanos o para el mismo juez, que sea un soporte del Estado democrático en la consecución de la independencia y armonía de los poderes públicos, que la decisión sea idealmente adecuada, lo importante también radica en la forma en que se toman las decisiones por parte de los tribunales constitucionales en tiempos actuales (MENDES, 2018).

Es el análisis de la forma, el raciocino de las decisiones y las preguntas ¿según quién? ¿cómo? ¿para quién?, a partir de las cuáles se puede determinar si un juez actúa con

${ }^{38}$ COLOMBIA. Corte Constitucional. Sentencia de Constitucionalidad 285 de 2016. Relator: M.P. Luis Guillermo Guerrero Pérez, Bogotá D.C, 1 de junio de 2016.

249 • R. Opin. Jur., Fortaleza, ano 19, n. 32, p.228-266, set./dez. 2021 
¿Independencia judicial según los jueces constitucionales? un análisis conceptual a partir de las decisiones del Supremo Tribunal Federal de Brasil y de la Corte Constitucional de Colombia

independencia o si simplemente está subordinado a cualquier otro elemento en perjuicio del orden legal y constitucional. Ciertas cuestiones hay que analizar en este punto.

En primer lugar, no es plausible que el mismo juez constitucional sea quién determine el alcance o contenido de su independencia, como ha sido evidenciado en la segunda parte de escrito. Esto obedece a unas razones. Entre otras, la condición humana del juez y la corrupción ética o material de la cual puede ser tentado. No significa entonces que se ponga en duda la probidad del juez, sólo que se reconoce que puede ser falible y que la misma naturaleza humana, como lo indica la concepción platónica, es deseada, apetitiva y en algunas ocasiones irracional (RAMOS- ALARCÓN, 2016, p. 197-228).

Por otro lado, si bien se garantiza la imparcialidad y la libre determinación del juez en el ejercicio de su función pública y el despliegue de su labor hermenéutico, su actuar esta ceñido a la sujeción del imperio de la Constitución y la ley. Por tal razón, quién determina el contenido, aristas o variables de la independencia del juez es su límite, la Constitución o la ley, razón que no es ajena a lo planteado por el Supremo Tribunal Federal cuando indicaba que era la ley la que debía cuidar que la independencia del juez sea garantizada en todas las causas, ${ }^{39}$ ese cuidado también se extiende en el ejercicio hermenéutico, pues como de alguna forma lo plantearía Mendes (2018), los tribunales constitucionales en su labor de hacer cumplir la Constitución debe seguir cierta metodología interpretativa para no temer sobre su actuar.

En un sentido similar, Aharon Barak plantea que en algunas ocasiones esta independencia se proporciona expresamente en la Constitución, inclusive, en ausencia de una disposición expresa, es un principio constitucional implícito en toda Constitución democrática. A su juicio, el comportamiento judicial debe estar gobernado por reglas de ética judicial para asegurar la independencia del juez. ${ }^{40}$

Por ejemplo, en decisión reciente del Supremo Tribunal Federal a través de la cual se buscaba cumplir mandatos de investigación, búsqueda y aprehensión en los gabinetes del Senador Fernando Bezerra Coelho y su hijo diputado, más allá de las críticas alrededor la

\footnotetext{
${ }^{39}$ BRASIL. Supremo Tribunal Federal. Ação Direta de Inconstitucionalidade no 4414. Relator: Ministro Luiz Fux. Brasil, Alagoas, 31 de maio de 2012. Supremo Tribunal Federal. Brasilia.

${ }^{40}$ Resulta pertinente resaltar que, el autor determina también que a partir del precedente se determinen presupuestos sobre la independencia del juez, no obstante aunque esta consideración es válida, su análisis en la mayoría del escrito se centra en la Corte Suprema de los Estados Unidos, o se centra en tribunales constitucionales de la familia del derecho consetudinario, los cuales, al seguir un modelo jurídico diferente, presenta matices que no serán desarrolladas en éste escrito, mismo siendo considerados por la jurisprudencia colombiana al darle valor al precedente y a las sentencias de unificación. Esto último ya está determinado en la ley, por ejemplo, la ley 1437 de 2011 art. 10 y la ley 169 de 1896 art. 4 (BARAK, 2002).
} 
solicitud expresa del titular de la acción penal, ${ }^{41}$ es interesante resaltar la nota publicada por el gabinete del ministro Barroso (2019) al indicar que la decisión fue puramente republicana, que no quiebra el principio de separación de los poderes, y que él como ministro, solo hace lo que es cierto, justo y legítimo.

Si el contenido de la separación de los poderes, de la independencia y autonomía del juez estuviese supeditado a lo que un juez en determinado momento considere que es "cierto, justo y legítimo", se infiere que quien bajo argumentos jurídicos no concuerde con la posición del juez constitucional, va en contravía de un "argumento republicano" o la "certeza, la justicia y la legitimidad".

Para ejemplificar el caso colombiano, la decisión sobre la constitucionalidad de las normas por las cuales se tiende a la implementación de un Plan Nacional de Electrificación Rural en el marco del Acuerdo de Paz para la construcción de una paz estable y duradera muestra como son los jueces quienes determinan ¿qué es la independencia judicial? Asimismo, presenta una discrepancia manifiesta bajo salvamento sobre el proceso de argumentación, la posible carga política y de conveniencia del fallo. Lo interesante a resaltar es como entre posición y contraposición, son los mismos ministros/magistrados los que deciden hasta dónde y qué representa esa independencia judicial. ${ }^{42}$

En segundo lugar, siguiendo el análisis sobre el ¿cómo se debe alcanzar o se garantiza esa independencia del juez? es necesario considerar que, atendiendo a la imparcialidad y a la objetividad, ya sea como facetas o componentes de la independencia judicial, el juez en el ejercicio de su función pública no puede tener intereses personales en el resultado, su función debe valorar y atender los valores aceptados en la sociedad, valorando el riesgo, que no sean objeto de populismo (cfr. SALGADO, 2018, p. 193; GABARDO, 2017, p. 65-91), de igual manera, si esos valores no son compartidos por su persona. Como lo resalta Aharon Barak, el juez debe tomar conciencia de que sus valores muchas veces pueden carecer de aceptación general, que sus opciones son excepcionales e inusuales (BARAK, 2002, p. 55; FREITAS, 2001, p. 13-35).

No obstante, esta necesidad de capacidad ética y personal obedece a una virtud humana y a la aplicación de esa virtud en el ejercicio de la función pública de administrar justicia. Que una persona reconozca su crítica es reconocer su humildad en la falibilidad, es

\footnotetext{
${ }^{41}$ El 19 de septiembre de 2019, la directoría del Conselho Federal da Ordem dos Advogados do Brasil publicó una nota de preocupación sobre la medida tomada por el Ministro Barroso: https://www.oab.org.br/noticia/57578/oab-nacional-divulga-nota-sobre-operacao-da-pf-no-congressonacional.

${ }^{42}$ COLOMBIA. Corte Constitucional. Sentencia de Constitucionalidad C- 565 de 2017, op. Cit. Ver en especial, el salvamento de voto de la Magistrada Gloria Stella Ortiz Delgado.
}

251 R. Opin. Jur., Fortaleza, ano 19, n. 32, p.228-266, set./dez. 2021 
¿Independencia judicial según los jueces constitucionales? un análisis conceptual a partir de las decisiones del Supremo Tribunal Federal de Brasil y de la Corte Constitucional de Colombia

una característica que distingue a hombres y mujeres virtuosos o virtuosas, quienes, aún formados bajo ciertas ideas, son sensibles hacia la dignidad de su cargo.

Vale la pena considerar que esos valores aceptados en la sociedad deben ser analizados con suma cautela. Tal es el caso de las decisiones sobre derechos reproductivos y el uso de la tecnología de reproducción humana y la utilización de embriones humanos congelados para investigaciones con células tronco-embrionarias destinadas a la búsqueda de curas contra enfermedades degenerativas, entre otros. ${ }^{43}$

En ese caso, el Supremo Tribunal Federal partió del análisis si la vida humana inicia con la concepción, después, si los óvulos fecundados pueden o no ser utilizados con fines científicos y/o terapias medicinales, pues iría en contravía o no del "derecho a la vida del embrión”. Fue una decisión que no se escapó de un debate religioso, con la participación de entidades eclesiásticas, a pesar de desarrollarse dentro de un Estado del que se defiende es laico. No obstante, la decisión demostró la importancia de los derechos de la mujer, de su dignidad, de su salud física y moral (Cfr. KREUZ, 2016; MACHADO; COOK, 2018, p. 185-231).

Así como de manera favorable el Supremo Tribunal Federal decidió a favor de la dignidad humana y la autonomía de la mujer, pudo también ser desfavorable prevalentemente con la misma, argumentando posiciones o valores morales y tradiciones propios de sociedades fuertemente religiosas. En últimas, lo que restringe el juicio hermenéutico, el despliegue pleno y subjetivo de las consideraciones del juez, así como los mismos valores de la sociedad, debe ser siempre la Constitución, la ley y la interpretación armónica e integral de sus disposiciones. Por ejemplo, no se puede seguir hablando de un estado laico si se llama a intervenir a una congregación religiosa sin importar el credo que profesan.

Aunque los ideales de Aharon Barak representan el ejemplo de un juez probo que hace parte de una democracia, la realidad cada vez es mas ajena a sus palabras. Véase como en Colombia, la ambición de un juez lo llevó a decidir a favor de una empresa petrolera sobre una acción de tutela o amparo que tenía por objeto la imposición de una cuantiosa multa. El hecho de recibir un dinero por su gestión lo llevó a ser el primer magistrado de la Corte Constitucional condenado penalmente en primera instancia, dejando a la Corte Constitucional en el inicio de un camino con una confianza en discusión. ${ }^{44}$

\footnotetext{
${ }^{43}$ BRASIL. Supremo Tribunal Federal. Ação Direta de Inconstitucionalidade no 3510, Distrito Federal. Relator: Min. Ayres Britto. Brasília, DF, 29 de mayo de 2008.

${ }^{44}$ Es necesario precisar que aunque la decisión fue recusada, la primera instancia, en compentencia de la Sala Especial de la Corte Suprema de Justicia lo ha encontrado responsable del delito de concusión. Disponible
} 
¿Qué hacer frente a esta situación? Las propuestas pueden resultar insuficientes, responder a cabalidad ¿cómo se puede garantizar esa independencia? requiere de consideraciones éticas que se escapan del objeto de este escrito, lo cierto, o en lo que por lo menos podría considerarse una opción, es el reconocimiento de que el juez reconozca que es parte de un sistema jurídico que establece una serie de factores que puede y no puede considerar, o por lo menos no puede tratar de inmiscuirse en un sistema que le es ajeno. Esto es, intentar adaptar un sistema común a un sistema sujetado sobre la ley. ${ }^{45}$

Por otro lado, como también lo resalta Barak (2002, p. 57), aunque alcanzar la objetividad completa es inalcanzable, por cuanto al expresar los valores fundamentales del sistema expresan lo que a su juicio parece adecuado y básico, - como fue expuesto a través de un ejemplo en este aparte-, no es deseable que lo haga. Lo deseable es, o más bien, en lo que podría contribuir sería en el fortalecimiento de la deliberación del juicio, en un acceso directo a los ciudadanos, no sólo desde la garantía del ejercicio de acción sino también desde el proceso de deliberación en su calidad de intervinientes ciudadanos, en la mayoría académicos o directamente implicados por la decisión, para que le brinden al juez constitucional, ex ante, elementos de juicio adicionales que le permitan adoptar una decisión. ${ }^{46}$ No obstante, esta intervención debe superar su único fundamento en el principio de igualdad de los intervinientes y de la libre expresión de las ideas en la deliberación. Para que la intervención en el proceso de deliberación judicial sea realmente efectiva debe otorgársele a las opiniones, los estudios y a las diferentes intervenciones, el rigor científico y epistemológico que comportan. Es decir, realmente deben influenciar la

en: https://www.asuntoslegales.com.co/actualidad/corte-suprema-de-justicia-condena-al-exmagistradojorge-pretelt-a-78-meses-de-prision-2945956

${ }^{45}$ Vale la pena destacar el análisis de Khristian Rodrigo Pscheidt, quién analizando el constitucionalismo judicial y el desvío democrático, evidencia la transmutación de la noción de separación de poderes, en supresión de la democracia, que ha dado paso a un judicial, en muchas veces, entidades técnicas no comprometidas con la democracia, quienes dirigen los aspectos socioeconómicos de la sociedad (PSCHEIDT, 2016, P. 36-48). Por otro lado, la posición que analiza la influencia del sistema central del constitucionalismo americano sobre las democracias liberales y la centralidad de los tribunales constitucionales en el ejercicio de la interpretación de la Constitución, es analizado por: (SANTOS, 2018, p. 23-44). Sobre el análisis de la capacidad creadora de los jueces, como sucede en el escenario americano: (CRISTIAN, 2015, p. 93-115).

${ }^{46}$ En Colombia, la Constitución de 1991 otorga la facultad a través del artículo 242 No. 1 bajo los siguientes términos: "Cualquier ciudadano podrá ejercer las acciones públicas previstas en el artículo precedente, e intervenir como impugnador o defensor de las normas sometidas a control en los procesos promovidos por otros, así como en aquellos para los cuales no existe acción pública". Véase también. COLOMBIA. Corte Constitucional. Sentencia de Constitucionalidad 194 de 2013. Relator: M.P: Luis Ernesto Vargas Silva, Bogotá D.C, 10 de abril de 2013. O para el caso de Brasil, la Ley 11.418 de 2006 que permitió en el análisis de las decisiones con repercusión general la intervención de terceros (amicus curiae). Vale la pena también considerar la obra de (ROA, 2019).

253 • R. Opin. Jur., Fortaleza, ano 19, n. 32, p.228-266, set./dez. 2021 
¿Independencia judicial según los jueces constitucionales? un análisis conceptual a partir de las decisiones del Supremo Tribunal Federal de Brasil y de la Corte Constitucional de Colombia

decisión judicial, los jueces deben superar su solipsismo (STRECK, 2011) y reconocer la necesidad del rigor técnico y científico que está por detrás de sus decisiones. ${ }^{47}$

En otras palabras, ¿hasta dónde puede ser plausible esa intervención de terceros para que la decisión del juez sea armoniosa e independiente? La respuesta al interrogante debe reconocer que la independencia no significa singularidad. El juez en la discriminación de factores que contaminan su decisión no puede ensimismarse en su función y decisión. El reconocimiento de terceros profesionales o directamente implicados son un elemento importante para que el juez se desprenda de lo que personalmente considere como justo para todos y atienda a lo que para legítimamente debería ser correcto.

Tampoco es deseable que la decisión del juez sea sometida, ex post, a un juicio de aprobación social que indague sobre la legitimidad o justicia de su decisión. Esto sería un factor que deslegitima y pone en riesgo su independencia. La justificación no siempre es la democracia de mayorías, aunque es el camino correcto y deseable, esa democracia está siendo lastimada por ataques populistas que obedecen a consideraciones políticas particulares.

Tal es el caso del Acto Legislativo (acto de reforma constitucional) 240 de 2019 que se tramitó sin éxito en Colombia, el cual, amparado bajo la idea del pueblo como constituyente primario, persiguió el objetivo de que cuando la Corte Constitucional mediante una decisión interprete materias referidas a los derechos fundamentales y a sus garantías, procedimientos de participación e institucionalidad legislativa, la ciudadanía podría solicitar mediante un referendo que se anule dicha interpretación si el pueblo la considera contraria a sus principios fundamentales.

Aunque desde una óptica democrática de control y salubridad de la función de administrar justicia la propuesta resulta a lo menos democráticamente viable, el hecho de que el control sea posterior, más allá de someter a gastos excesivos pecuniarios o no la función constitucional de administrar justicia, se entraría en un escenario en donde una sociedad volatilizada, susceptible de populismos, someta una posible decisión en derecho a una voluntad política particular y arbitraria. Lo deseable sería profesionalizar y hacer participativo el proceso deliberativo constitucional, ex ante y que esas consideraciones de terceros sean valoradas a partir del cuerpo colegiado, para que quién tenga la competencia de proyectar la decisión trate de ceñir su independencia a lo que la Constitución y la ley exige.

\footnotetext{
${ }^{47} \mathrm{Un}$ argumento en contrario devendría en intervenciones públicas, y en general, audiencias públicas incoherentes e inconsistentes, tal como lo demuestra el estudio de (LEAL; HERY; MASSADAS, 2018) a diez años de la primera audiencia pública ante el Supremo Tribunal Federal.
} 
En tercer lugar, ¿para quién se debe garantizar esa independencia judicial? La única respuesta que tiene cabida en este escenario es para la sociedad, el pueblo. No obstante, es para una sociedad en sentido colectivo, más allá de la individual. Ya que, los fines del Estado son para ser cobijados por todos, incluso para aquellos que no tienen acceso a la justicia.

Resulta imperante el análisis de Daniel Wunder Hachem, quién analiza el Derecho Público brasilero posterior a la Constitución de 1988, caracterizado por una expresiva ampliación de intervención judicial, principalmente, en lo que se refiere a la concesión de prestaciones estatales positivas dirigidas a la garantía efectiva de los derechos fundamentales sociales. En el caso concreto de los pedidos de tratamientos de salud de alto costo se analiza que el Supremo Tribunal Federal optó por una postura que muchas veces corresponde con decisiones desmedidas e incongruentes, perjudiciales para la implementación, ejecución y seguimiento de las políticas públicas, invadiendo la función y la acción administrativa que debe estar orientada a la universalidad de la población, perjudicando también el empleo racional de los recursos públicos (HACHEM, 2013, p. 340-399).

Siguiendo al autor, la efectivación de los derechos fundamentales sociales limitados a la vía del poder judicial, implicaría una atribución de privilegios a pocos individuos que tienen condiciones de acceso a la jurisdicción en perjuicio de los ciudadanos en general, quienes no cuentan con la información, el conocimiento o los medios financieros suficientes, quienes aún depende de los programas y proyectos sociales de la Administración Pública (HACHEM, 2013, 351; AVILA; MELO, 2018, p. 83).

Un análisis teórico que puede contribuir al estudio sobre el peligro de la extensión del poder judicial o cualquier otro poder, presentado por Jeremy Waldron y propuesto como principio negativo por Emmanuel Joseph Sieyès, quién en desarrollo de la teoría sobre le pouvoir constituant, indicaba que en un sistema constitucional, la idea debe ser que ningún poder constituido pueda identificarse o se identifique a sí mismo, ya sea directa o indirectamente con el pueblo, reivindicando una credencial de soberano popular o su único protector. La idea de la voz del pueblo debe estar ceñido a procedimientos o parámetros establecidos, sin resaltar u otorgar un estatus especial a alguno de los poderes. ${ }^{48}$

Así, si se otorga mayor relevancia al poder judicial, a los tribunales constitucionales como pouvoir constitué, y además, se considera que son los únicos guardianes de la Constitución y, por tanto, son los únicos llamados a reivindicar las garantías y los derechos fundamentales de los ciudadanos a través de sus propias interpretaciones, la respuesta,

${ }^{48} \mathrm{El}$ análisis de la obra de Sieyès, desde una perspectiva del poder judicial, concretamente de los tribunales constitucionales, fue elaborada por (WALDRON, 2018).

255 • R. Opin. Jur., Fortaleza, ano 19, n. 32, p.228-266, set./dez. 2021 
¿Independencia judicial según los jueces constitucionales? un análisis conceptual a partir de las decisiones del Supremo Tribunal Federal de Brasil y de la Corte Constitucional de Colombia

como lo plantea Jeremy Waldron, no solo está en un consejo a los jueces que dejen una especie "activismo" de su trabajo y se sujeten a la Constitución, pues la democracia estaría sujeta a su voluntad. Por el contrario, resultaría útil que la carta de derechos restrinja y concretice la separación de las competencias institucionales para su garantía, sean integrados y políticamente coherentes (WALDRON, 2018, p. 141-145).

En otras palabras, si la supremacía de los tribunales constitucionales comienza a evidenciarse cuando piensan y se presentan persiguiendo un programa o una política coherente, debe optar por limitar su respuesta a la medida que surgen los abusos particulares identificados en la Constitución. La visión de que los jueces deben tener una visión integral de la Constitución como un todo y que sobre ella definen su independencia, debe ser matizada siempre sobre la consideración garante de los derechos sociales fundamentales de manera sucesiva, sin injerencia en la ejecución de estos, dejando de atribuirse funciones no constituyentes, permitiendo que las ramas electas de gobierno también tomen y ejecuten sus propias decisiones (WALDRON, 2018, p. 150). Sin duda, una propuesta que va más allá de definir su propia independencia e invita a ver y analizar el estatus y actualidad de la Constitución orgánica en tiempos contemporáneos.

\section{CONSIDERACIONES FINALES}

El reconocimiento del principio de separación de los poderes, de la independencia judicial, la autonomía de los jueces y la imparcialidad en el ejercicio de la función pública de administrar justicia representa una garantía fundamental para la democracia en el Estado Social de Derecho. Su amplio desarrollo teórico obedece a los movimientos constitucionales propios de cada Estado, que, llegada su necesaria referencia, se pone sobre la mesa y se erige como un principio inviolable frente a cualquier reforma o propuesta que haga referencia al mismo o a sus manifestaciones.

Sin duda, lo expuesto en el párrafo anterior es lo que coincide con un sistema democrático para el adecuado andamiaje de la democracia. No obstante, la preocupación empieza a surgir cuando los directamente implicados o relacionados con el principio lo invocan a su manera, lo caracterizan bajo su consideración, o lo atribuyen al poder constituyente originario, el pueblo, para buscar legitimidad en lo que entienden sobre la independencia judicial.

Tal es el caso del ¿cómo? ¿hasta dónde? ¿qué? ¿para quién? interrogantes sobre los

que se pretende entender el principio de independencia judicial por parte de los tribunales 
constitucionales, en concreto, del Supremo Tribunal Federal de Brasil y de la Corte Constitucional de Colombia.

Inicialmente, el presente trabajo analizó algunos presupuestos teóricos de la independencia judicial en el Estado Social de Derecho, tomando en consideración lo que puede ser una construcción histórica propia de dos sistemas jurídicos. Uno continental y otro consuetudinario. Esto permitió a su vez, identificar cómo son vistos cada uno de ellos desde distintas perspectivas. Con todo, los presupuestos que arrojan esas consideraciones son uniformes: Un juez independiente de las otras ramas del poder público, sin ningún tipo de provocación o injerencia, autónomo en el ejercicio de sus funciones autónomas, garante de los postulados normativos per se, de las garantías constitucionales fundamentales.

Amparado en esos presupuestos, con matices, muchas de ellas exorbitantes, se identificó como el Supremo Tribunal Federal de Brasil y la Corte Constitucional de Colombia han definido, muchas veces reiterado, en otras veces discordado, sobre los presupuestos, el concepto, la naturaleza de principio, las características, tipologías, sentidos y facetas de la independencia judicial. Generándose así una evidente autonomía y una indiscriminada referencia del concepto, de acuerdo con sus consideraciones temporales y amoldando los casos propuestos a lo que a su juicio es la independencia judicial.

En últimas, las cuestiones de ¿qué? ¿cómo? ¿para quién? alrededor del principio de la independencia judicial no encuentra un soporte más allá que la misma Constitución y la ley, por lo que no es dado a los mismos jueces definir sobre el alcance o contenido de la independencia judicial, so pena de que por su condición humana desplieguen una subjetividad invocada en lo que para ellos es justo y legítimo en determinado momento.

Además, ese ¿qué? sujeto a la Constitución y a la ley, también debe atender con cautela a lo que para la sociedad es justo o legítimo en cierto momento, pues la volatilidad del pensamiento ciudadano, la susceptibilidad de los movimientos y las transformaciones sociales, pueden ser invocadas como legítimas entre los mismos jueces, inclusive no siéndolo, en perjuicio de otros, lo que es propio de un moralismo que se ha venido infiltrando en la institucionalidad colombiana y brasilera.

Por otro lado, el ¿cómo se debe alcanzar o garantizar esa independencia del juez? no solo debe considerar la imparcialidad y objetividad como facetas del principio, porque estas mismas resultan insuficientes para garantizar la plena independencia, igualmente, al considerar que la intangibilidad de los presupuestos éticos tienen dificultad al ser normativamente descritos, por tal, la deliberación y la participación directa de ciudadanos y científicos durante el proceso y ejercicio deliberativo resulta una idea sana y racional 
¿Independencia judicial según los jueces constitucionales? un análisis conceptual a partir de las decisiones del Supremo Tribunal Federal de Brasil y de la Corte Constitucional de Colombia

siempre y cuando, además de fundamentarse en la igualdad y la libertad de expresión, reconozca el valor científico y epistemológico del contenido de estas intervenciones.

El ipara quién debe garantizarse la independencia judicial? Parece tener una respuesta viable, la sociedad, el pueblo. Pero no sólo el pueblo que tiene acceso y conocimiento a la justicia, que es significativamente menor al que no tiene ni conocimiento ni posibilidades acceso. El objetivo de la justicia para todos no solo depende del juez y del poder judicial. Es una obligación y un deber constitucional de las otras ramas del poder publico. La planeación, proyección y ejecución de políticas y estructuras de acceso a la justicia envuelve la actuación y participación del Ejecutivo y del Legislativo. La independencia judicial no puede justificarse en una defensa única sobre el poder constituyente originario garantizado por el poder judicial al argumentar que es superior a los otros. Así, impide la colaboración armoniosa de los mismos poderes y la garantía plena y efectiva de los derechos sociales fundamentales. En últimas, la idea de la independencia judicial no sólo es de los jueces, es de todos, y lo importante radica en que se piensen mecanismos adecuados para que el principio sea material.

Finalmente, otro elemento que cabe a la respuesta de esa última pregunta debe considerar la confianza judicial. De nada sirve una garantía plena, efectiva y espontánea del acceso a la justicia si la confianza sobre los jueces es nula o está nublada. ¿El pueblo confía en sus jueces? El hecho de que los americanos del siglo XIX reafirmaran esa confianza o los revolucionarios franceses la desmintieran, no quiere decir que la constante en los ordenamientos jurídicos sobre los que tuvieron influencia mantenga esa ambivalencia. A diferencia de las colombianas y colombianos, que aún confían en la actuación de la justicia constitucional, ${ }^{49}$ Brasil enfrenta, entre otros males, un solipsismo judicial (STRECK, 2011). El riesgo de que la confianza descienda a su nivel más bajo, como ocurrió en países y fenómenos recientes en Polonia, Hungría, Bolivia, Nicaragua o Venezuela u Honduras, no es un hecho cuya ocurrencia sea totalmente ajena a Colombia y Brasil. En ese sentido, la importancia de leer y entender la independencia judicial como una garantía ciudadana, que le de voz a todas y todos, cuyo soporte sea la Constitución y la ley.

\footnotetext{
${ }^{49}$ Una manifestación de esta confianza es la conformación en la opinión ciudadana de una idea según la cual, si los problemas no tienen solución viable, la acción de tutela y otros mecanismos constitucionales pueden dar una salida. Esta idea se fortalece con el carácter progresista que identifica a la Corte Constitucional durante los últimos años.
} 


\section{REFERENCIAS}

AVILA, Ana Paula Oliveira; MELO, Karen Cristina Correa de. Separação de poderes e diálogos institucionais nos litígios envolvendo o direito à saúde. Revista de Investigações Constitucionais, Curitiba, v. 5, n. 1, p. 83-108, jan./abr. 2018. DOI: 10.5380/rinc.v5i1.54934.

BACHOF, Otto. Grundgesetz und Richtermacht. En: WEGE zum Rechtsstaat. Königstein im Taunus, 1979.

BARAK, Aharon. A judge on judging: the role of a supreme court in a democracy. Harvard Law Review, Boston, v. 116, n. 20, p. 1-345, jan. 2002.

BARROSO, Luis Roberto. Nota à imprensa. 2019. Disponible en: http://www.Supremo TribunalFederal.jus.br/arquivo/cms/noticiaNoticiaSupremoTribunalFederal/anexo/NotaI mprensa.pdf. Acesso em: 21 jan. 2020.

BRASIL. Constitución (1988). Constitución de la República Federativa del Brasil de 1988. Brasilia, DF: Presidência da República, 1988.

BRASIL. Supremo Tribunal Federal. Ação Direta de Inconstitucionalidade ${ }^{\circ}$ 135-3, Paraíba. Requerente: Associação dos Magistrados Brasileiros -AMB. Relator: Min. Octavio Galloti. Brasília, DF, 21 de novembro de 1996. Brasília, 15 agosto 1997.

BRASIL. Supremo Tribunal Federal. Ação Direta de Inconstitucionalidade no 98-5, Mato Grosso. Requerente: Procurador-Geral da República. Relator: Min. Sepúlveda Pertence. Brasília, DF, 07 de agosto de 1997. Brasília, 31 out. 1997

BRASIL. Supremo Tribunal Federal. Ação Direta de Inconstitucionalidade no 3367-1. Distrito Federal. Requerente: Associação dos Magistrados Brasileiros - AMB. Relator: Min. Cezar Peluso, DF, 13 de abril de 2005. Brasília, 22 setembro de 2006.

BRASIL. Supremo Tribunal Federal. Ação Direta de Inconstitucionalidade $\mathbf{n}^{\circ}$ 3510, Distrito Federal. Relator: Min. Ayres Britto. Brasília, DF, 29 de mayo de 2008. Brasília.

BRASIL. Supremo Tribunal Federal. Ação Direta de Inconstitucionalidade $\mathrm{n}^{\circ}$ 1.578-8, Alagoas. Requerente: Associação dos Magistrados Brasileiros - AMB. Relator: Min. Carmen Lúcia. Brasília, DF, 04 de março de 2009. Brasília, 3 de abril de 2009. 
¿Independencia judicial según los jueces constitucionales? un análisis conceptual a partir de las decisiones del Supremo Tribunal Federal de Brasil y de la Corte Constitucional de Colombia

BRASIL. Supremo Tribunal Federal. Acórdão no 2699-9. Relator: Celso de Mello. Brasília, DF, 12 de março de 2019. Quest. Ord. em Inquérito 2.699-9 Distrito Federal. Brasília, 08 mayo 2009.

BRASIL. Supremo Tribunal Federal. Ação Direta de Inconstitucionalidade $n^{\circ} 4414$. Relator: Ministro Luiz Fux. Brasil, Alagoas, 31 de maio de 2012. Brasília.

BRASIL. Supremo Tribunal Federal. Medida cautelar na Ação Direta de Inconstitucionalidade $\mathbf{n}^{\circ}$ 5.104, Distrito Federal. Requerente: Procurador-Geral da República. Min. Roberto Barroso. Brasília, DF, 21 de maio de 2014. Brasília, 30 outubro 2014.

BRASIL. Supremo Tribunal Federal. Ação Direta de Inconstitucionalidade $\mathbf{n}^{\circ}$ 183-3, Mato Grosso. Relator: Min. Sepúlveda Pertence; BRASIL. Supremo Tribunal Federal. BRASIL. Mandado de Segurança no 30819. Relator: Min. Luiz Fux. Brasília, DF, 22 de abril de 2015. Brasília, 28 abr. 2015.

BRASIL. Supremo Tribunal Federal. Medida cautelar na Ação Direta de Inconstitucionalidade no 5316, Distrito Federal. Requerente: Associação dos Magistrados Brasileiros - AMB. Relator: Min. Luiz Fux. Brasília, DF, 21 de maio de 2015. Brasília, 06 out. 2015.

COOK, Ramsay; DIETZE, Gottfried. The Federalist: A Classic on Federalism and Free Government. The Canadian Journal of Economics and Political Science, v. 27, n. 3, p.420-422, Aug. 1961. JSTOR. http://dx.doi.org/10.2307/139620.

COLOMBIA. Constitución (1991). Constitución, de 25 de julho de 1991. Constitución Política de Colombia. Bogotá D.C.

COLOMBIA. Ley No. 169, de diciembre 31 de 1986. Sobre reformas judiciales. Bogotá D.C

COlOMBIA. Ley No. 270, del 7 de marzo de 1996. Estatutaria de la Administración de Justicia. Bogotá D.C

COLOMBIA. Ley n ${ }^{\circ}$ 1437, de 18 de janeiro de 2011. Por la cual se expide el código de Procedimiento Administrativo y de Lo Contencioso Administrativo. Bogotá D.C.

COLOMBIA. Corte Constitucional. Sentencia de Constitucionalidad 037 de 1996. Relator: M.P. Vladimiro Naranjo Mesa, Bogotá D.C, 5 de febrero de 1996. 
COLOMBIA. Corte Constitucional. Sentencia de Constitucionalidad 1643 de 2000. Relator (encargado): M.P. Jairo Charry Rivas, Bogotá D.C, 29 de noviembre de 2000.

COLOMBIA. Corte Constitucional. Sentencia de Constitucionalidad 836 de 2001. Relator: M.P. Rodrigo Escobar Gil, Bogotá D.C, 9 de agosto de 2001.

COlOMBIA, Corte Constitucional. Sentencia de Tutela 1031 de 2001. Relator: M.P. Eduardo Montealegre Lynett, Bogotá D.C, 27 de septiembre de 2001.

COLOMBIA. Corte Constitucional. Sentencia de Tutela 593 de 2002. Relator: M.P. Manuel José Cepeda Espinosa, Bogotá D.C, 01 de agosto de 2002.

COlOMBIA. Corte Constitucional. Sentencia de Constitucionalidad 1024 de 2002. Relator: M.P. Alfredo Beltrán Sierra. Bogotá D.C, 26 de noviembre de 2002.

COLOMBIA, Corte Constitucional. Sentencia de Tutela 096 de 2003. Relator: M.P. Jaime Araujo Rentería, Bogotá D.C, 20 de octubre de 2003.

COlOMBIA. Corte Constitucional. Sentencia de Tutela 1165 de 2003. Relator: M.P. Rodrigo Escobar Gil, Bogotá D.C, 4 de diciembre de 2003.

COlOMBIA. Corte Constitucional. Sentencia de Constitucionalidad C-971 de 2004. Relator: M.P. Manuel José Cepeda Espinosa, Bogotá D.C, 7 de octubre de 2004.

COlOMBIA. Corte Constitucional. Sentencia de Constitucionalidad 888 de 2004. Relator: M.P: Clara Inés Vargas Hernández, Bogotá D.C, 14 de septiembre de 2004.

COlOMBIA. Corte Constitucional. Sentencia de Tutela 302 de 2006. Relator: M.P. Rodrigo Escobar Gil, Bogotá D.C, 7 de abril de 2006.

COLOMBIA. Corte Constitucional. Sentencia de Tutela 284 de 2006. Relator: M.P: Clara Inés Vargas Hernández, Bogotá D.C, 5 de abril de 2006.

COLOMBIA. Corte Constitucional. Sentencia de Tutela 191 de 2009. Relator: M.P. Luis Ernesto Vargas Silva, Bogotá D.C, 20 de marzo de 2009.

COLOMBIA. Corte Constitucional. Auto 169 de 2009. Relator: M.P: Luis Ernesto Vargas Silva, Bogotá D.C, 29 de abril de 2009.

COlOMBIA. Corte Constitucional. Sentencia de Constitucionalidad 540 de 2011. Relator: M.P. Jorge Ignacio Pretelt Chaljub, Bogotá D.C, 6 de julio de 2011.

261 - R. Opin. Jur., Fortaleza, ano 19, n. 32, p.228-266, set./dez. 2021 
¿Independencia judicial según los jueces constitucionales? un análisis conceptual a partir de las decisiones del Supremo Tribunal Federal de Brasil y de la Corte Constitucional de Colombia

COlOMBIA. Corte Constitucional. Sentencia de Constitucionalidad 881 de 2011. Relator: M.P: Luis Ernesto Vargas Silva, Bogotá D.C, 23 de noviembre de 2011.

COlOMBIA, Corte Constitucional. Sentencia de Constitucionalidad 288 de 2012. Relator: M.P. Luis Ernesto Vargas Silva, Bogotá D.C, 18 de abril de 2012.

COlOMBIA. Corte Constitucional. Sentencia de Constitucionalidad 194 de 2013. Relator: M.P: Luis Ernesto Vargas Silva, Bogotá D.C, 10 de abril de 2013.

COLOMBIA. Corte Constitucional. Sentencia de Tutela 107 de 2014. Relator: M.P. Luis Ernesto Vargas Silva, Bogotá D.C, 28 de febrero de 2014.

COlOMBIA. Corte Constitucional. Sentencia de Constitucionalidad 870 de 2014. Relator: M.P. Luis Guillermo Guerrero Pérez, Bogotá D.C, 13 de noviembre de 2014.

COlOMBIA. Corte Constitucional. Sentencia de Constitucionalidad 373 de 2016. Relator: M.P. Alejandro Linares Cantillo y Gabriel Eduardo Mendoza Martello, Bogotá D.C, 13 de julio de 2016.

COlOMBIA. Corte Constitucional. Sentencia de Constitucionalidad 285 de 2016. Relator: M.P. Luis Guillermo Guerrero Pérez, Bogotá D.C, 1 de junio de 2016.

COlOMBIA. Corte Constitucional. Sentencia de Constitucionalidad C- 565 de 2017. Relatora: MP. Diana Fajardo Rivera, Bogotá D.C, 8 de septiembre de 2017.

COLOMBIA. Corte Constitucional. Sentencia de Tutela 450 de 2018. Relator: M.P. Luis Guillermo Guerrero Pérez, Bogotá D.C, 19 de noviembre de 2018.

CRISTÁN, Estela B. ¿Jueces legisladores? Revista de Investigações Constitucionais, Curitiba, v. 2, n. 2, p. 93-115, maio/ago. 2015. DOI: http://dx.doi.org/10.5380/rinc.v2i2.44512.

FREITAS, Juarez. O intérprete e o poder de dar vida à Constituição: preceitos de exegese constitucional. $\mathrm{A} \& \mathrm{C}$ - Revista de Direito Administrativo \& Constitucional, Curitiba, v. 8, n. 2, p. 13-35, 8 jan. 2001. http://dx.doi.org/10.21056/aec.v0i0.753.

GABARDO, Emerson. O jardim e a praça para além do bem e do mal: uma antítese ao critério de subsidiariedade como determinante dos fins do Estado Social. 2009. 409 f. Tese (Doutorado) - Curso de Direito, PPGD, Universidade Federal do Paraná, Curitiba, 2009. 
GABARDO, Emerson. Os perigos do moralismo político e a necessidade de defesa do direito posto na Constituição da República de 1988. A\&C - Revista de Direito Administrativo \& Constitucional, Belo Horizonte, v. 17, n. 70, p. 65-91, out./dez. 2017.

GARCÍA, José Francisco. Tres aportes fundamentales de El Federalista a la teoría constitucional moderna. Revista de Derecho, Valdivia, v. 1, p. 33-59, jul. 2007.

HACHEM, Daniel Wunder. A maximização dos direitos fundamentais econômicos e sociais pela via administrativa e a promoção do desenvolvimento. Revista de Direitos Fundamentais e Democracia, Curitiba, v. 13, n. 13, p. 340-399, jan./jun. 2013.

HACHEM, Daniel Wunder. A dupla titularidade (individual e transindividual) dos direitos fundamentais econômicos, sociais, culturais e ambientais. Revista de Direitos Fundamentais e Democracia, Curitiba, v. 14, n. 14, p. 618-688, jul./dez. 2013.

HAMILTON, Alexander; MADISON, James; JAY, Jhon. El Federalista. Santiago de Chile: Instituto de Estudios de la Sociedad, 2018.

JEFFERSON, Thomas. Notes on the State of Virginia. [S.l.]: Andesite Press, 2017.

KREUZ, Letícia Regina Camargo. Crime e Pecado: o aborto sob os véus da religiosidade, da moralidade, da juridicidade e do feminismo. 2016. 235 f. Dissertação (Mestrado) - Curso de Mestrado em Direito, PPGD, Universidade Federal do Paraná, Curitiba, 2016.

LEAL, Fernando; HERDY, Rachel; MASSADAS, Júlia. Uma década de audiências públicas no Supremo Tribunal Federal (2007-2017). Revista de Investigações Constitucionais, Curitiba, v. 5, n. 1, p. 331-372, jan./abr. 2018. DOI: 10.5380/rinc. v5i1.56328.

LÖSING, Norbert. Independencia y función del Poder Judicial en el Estado democrático de derecho. In: KONRAD ADENAUER STIFTUNG (Montevideo). Anuario de Derecho Constitucional Latinoamericano. Montevideo. 2011. p. 413-428. (Anuario de Derecho Constitucional).

MACHADO, Marta Rodriguez de Assis; COOK, Rebecca J. Constitutionalizing abortion in Brazil. Revista de Investigações Constitucionais, Curitiba, v. 5, n. 3, p. 185-231, set./dez. 2018. DOI: 10.5380/rinc.v5i3.60973.

MENDES, Conrado Hübner. Cortes Constitucionales y democracia deliberativa. Traducción Diego Andrés Gonzalez Medina. Madrid: Marcial Pons, 2018. 
¿Independencia judicial según los jueces constitucionales? un análisis conceptual a partir de las decisiones del Supremo Tribunal Federal de Brasil y de la Corte Constitucional de Colombia

ORJUELA, Luis Javier. Así era el país en el que nació la Carta del 91 ¿Por qué y para qué se llegó a la convocatoria de una Asamblea Nacional Constituyente? In: DEPARTAMENTO DE CIENCIA POLÍTICA. Facultad de Ciencias Sociales Universidad de Los Andes (Ed.). Constitución de 1991, 20 años logros y pendientes. Bogotá D.C: Universidad de Los Andes, El Tiempo, 2011. p. 6-8.

PSCHEIDT, Khristian Rodrigo. Constitucionalismo judicial: o desvio democrático. Revista de Direito Econômico e Socioambiental, Curitiba, v. 7, n. 2, p. 36-48, jul./dez. 2016. doi: 10.7213/rev.dir.econ.socioambienta.07.002.AO03.

RAMOS-ALARCÓN, Luis. La ambición en las filosofías morales y políticas de Platón y Maquiavelo. En: BENITEZ, Laura; TOLEDO, Leonel, VELÁZQUEZ, Alejandra (coords.). Episodios filosóficos del platonismo: ecos y tensiones. México: UNAM-DGAPA-Torres Asociados, 2016. p. 197-228.

REMÉDIO JÚNIOR, José Ângelo. O princípio de socialidade e direitos metaindividuais: responsabilidade social. Revista de Direito Econômico e Socioambiental, Curitiba, v. 2, n. 2, p. 307-337, jul. 2011. Disponível em: https://periodicos.pucpr.br/index.php/direitoeconomico/article/view/6236/6158. Acesso em: 21 jan. 2020.

ROA, Jorge. Control de Constitucionalidad deliberativo: el ciudadano ante la justicia constitucional, la Acción Pública de inconstitucionalidad y la legitimidad democrática del control judicial al legislador. Bogotá D.C: Universidad Externado de Colombia, 2019.

SAFFON, Maria Paula; GARCÍA-VILLEGAS, Mauricio. Derechos sociales y activismo judicial: la dimensión fáctica del activismo judicial en derechos sociales en Colombia. Estudios Socio-Jurídicos, v. 13, n. 1, p. 75-107, mayo 2011. ISSN 2145-4531. Disponível em: https://revistas.urosario.edu.co/index.php/sociojuridicos/article/view/15 11/1404. Acesso em: 21 jan. 2020.

SALGADO, Eneida Desiree. Os limites explícitos e implícitos aos processos formais e informais de mudança da Constituição: ensaio em defesa do constitucionalismo e da democracia. A\&C - Revista de Direito Administrativo \& Constitucional, Belo Horizonte, v. 12, n. 48, p. 159-176, abr./jun. 2012.

SALGADO, Eneida Desiree. Populismo judicial, moralismo e o desprezo à Constituição: a democracia entre velhos e novos inimigos. Revista Brasileira de Estudos Políticos, n. 117, p. 193-217, jul./dez. 2018. http://dx.doi.org/10.9732/p.0034-7191.2018v117p193. 
SANTOS, Pedro Felipe de Oliveira. O futuro da jurisdição constitucional: as aspirações do constitucionalismo global no paradigma do engajamento comparativo. Revista do Tribunal Regional Federal da Primeira Região, Brasília, v. 30, n. 1, p. 23-44, jan. 2018.

STRECK, Lenio Luiz. A interpretação do direito e o dilema acerca de como evitar juristocracias: a importância de Peter Häberle para a superação dos atributos (Eigenschaften) solipsistas do direito. Observatório da Jurisdição Constitucional, Brasília, v. 4, n. 1, p. 1-32, 2010/2011. Disponível em: https://www.portaldeperiodicos.idp.edu.br/observatorio/article/view/561/373. Acesso em: 15 dez. 2020.

TOCQUEVILLE, Alexis de. La democracia en América. México: Fondo de Cultura Económica, 2019.

TRINDADE, André; OLIVEIRA, Rafael. O ativismo judicial na débâcle do sistema político: sobre uma hermenêutica da crise. Revista eletrônica do curso de Direito da UFSM, v. 11, n. 2, p. 751-772, $2016 . \quad$ Disponível em: https://periodicos.ufsm.br/revistadireito/article/view/22912/pdf. Acesso em: 21 jan. 2020.

VIEIRA, Oscar Vilhena. Supremocracia. Revista Direito GV, Rio de Janeiro, v. 4, n. 2, p. 441-464, jul. 2008. Disponible en: http://bibliotecadigital.fgv.br/ojs/index.php/revdireitogv/article/view/35159/33964

WALDRON, Jeremy. Contra el gobierno de los jueces: ventajas y desventajas de tomar decisiones por mayoría en el Congreso y en los Tribunales. Buenos Aires: Siglo XXI Editores, 2018. (Derecho y Política). Edición de Juan F. González Bertomeu.

\section{NOTA}

Declaramos para los fines debidos que el artículo intitulado ¿Independencia judicial según los jueces constitucionales? Un análisis conceptual a partir de las decisiones del Supremo Tribunal Federal de Brasil y de la Corte Constitucional de Colombia, enviado a la Revista Opinião Jurídica, es fruto de las investigaciones desarrolladas y adelantadas por los autores en el marco de las discusiones sobre Justicia Constitucional Comparada del grupo de investigación NUPED (Núcleo de Pesquisas em Políticas Públicas e Desenvolvimento Humano) adscrito al Programa de Pós-graduação de la Pontifícia Universidade Católica do Paraná - PUCPR junto con investigadores de la Universidad del Rosario y Externado de Colombia. En ese sentido, la proyección, ejecución y revisión del artículo se dio de la 
¿Independencia judicial según los jueces constitucionales? un análisis conceptual a partir de las decisiones del Supremo Tribunal Federal de Brasil y de la Corte Constitucional de Colombia

siguiente manera: 1) William Iván Gallo Aponte, además del apoyo en la redacción y traducción al español de los apartes correspondientes, de la lectura final y la revisión de las evaluaciones, realizó, preparó y organizó la investigación jurisprudencial de las decisiones de la Corte Constitucional de Colombia; 2) Daniel Castanha de Freitas se encargó de la investigación sobre las decisiones del Supremo Tribunal Federal de Brasil y de dar soporte a la estructuración metodológica del artículo con la investigación jurisprudencial dada; 3) Vivian Cristina Lima López Valle, además de verificar la estructura metodológica, canalizó los puntos del diálogo y comparación entre las decisiones, suministró material bibliográfico y contribuyó el la redacción de los presupuestos teóricos para dar introducción, crítica y conclusión a las ideas desarrolladas. Al final, realizó la revisión final para el envío.

\section{Como citar este documento:}

GALLO APONTE, William Iván; FREITAS, Daniel Castanha de; VALLE, Vivian Cristina Lima López. ¿Independencia judicial según los jueces constitucionales? un análisis conceptual a partir de las decisiones del Supremo Tribunal Federal de Brasil y de la Corte Constitucional de Colombia. Revista Opinião Jurídica, Fortaleza, v. 19, n. 32, p. 228-266, set./dez. 2021. 